\title{
INTRODUCING FINANCIAL ASSETS INTO STRUCTURAL MODELS
}

\author{
INTRODUCCION DE ACTIVOS FINANCIEROS EN MODELOS \\ ESTRUCTURALES
}

\section{JORGE FORNERO*}

Central Bank of Chile

\begin{abstract}
This paper reviews extensively the literature on asset pricing and builds a structural dynamic general equilibrium model with financial assets. We obtain the policy function of the calibrated model and approximate it up to third order. We derive asset pricing and various premiums conditions up to the third order, meaning that returns depend on the first three conditional moments. We obtain a hypothetic yield curve whose curvature increases with the order of the approximation because of the premiums. In addition, impulse response functions of various fundamental shocks illustrate the effect on the level and slope of bond yields with several maturities and on breakeven inflation. Important shocks are technology and inflation target shocks.
\end{abstract}

Keywords: financial assets, DSGE, business cycle, monetary policy.

JEL Classification: G1, E3.

\section{Resumen}

Este trabajo hace una revisión extensiva de la literatura sobre fijación de precios de activos financieros. Estos se introducen en un modelo macroestructural de equilibrio general estándar. La función de política del modelo

* Corresponding email from the author: jfornero@bcentral.cl. The views expressed in this paper are those of the author and do not necessarily reflect the views of the Central Bank of Chile. The usual disclaimer applies. I thank comments by Juan Pablo Medina, Claudio Soto and an anonymous referee and to Juan Sebastian Becerra for research assistance. 
calibrado es aproximada hasta el tercer orden. Se derivan aproximaciones de las fórmulas de valuación de activos financieros y de los premios, que dependen de los primeros tres momentos condicionales. Se obtiene una curva hipotética de retorno de bonos donde la curvatura aumenta con una aproximación de orden mayor por efecto de premios. Adicionalmente, funciones de impulso respuesta de varios shocks estructurales ilustran los efectos en el nivel y en la pendiente de los retornos de bonos con distinta madurez y en la compensación inflacionaria. Los shocks más importantes son a la tecnología y a la meta de inflación.

Palabras Clave: Activos financieros, modelos DSGE, ciclo de negocios, política monetaria.

Clasificación JEL: G1, E3.

\section{INTRODUCTION}

Someone not familiar with asset pricing theory would have to be quite selective in approaching the topic, due to the large number of models and the varied methods of estimation. Besides, the tradition has been to study asset pricing in parsimonious models with a highly simplified vision of the macroeconomic context. Recently, the emphasis has been placed on general equilibrium analysis implemented in a structural model that includes fixed-income securities as well as stocks. In this way, the model will clarify the reasons why asset prices change, which is of primary interest to shape policy makers' interpretation about the workings of financial markets. However, it has been difficult for structural models to reproduce basic features of asset prices such as their volatility and their correlation with macroeconomic variables.

The objective of this paper is to review the literature and to make clear how financial variables are linked with macroeconomic ones in a non-linear structural model. Provided the solution method preserves the model's non-linearities, then it will be able to account for excess returns in stocks (the equity premium) and bonds (the risk premium).

Several choices are made to formalize a structural model such as preferences, technology, the policy framework, the degree of integration of domestic assets and goods markets ${ }^{1}$. It is instructive, then, to consider how the policy framework conditions of the monetary policy (MP) propagation mechanism motivate the importance of financial assets. The inflation targeting implementation of MP consists of Central Banks (CBs) that announce in advance accomplishable targets that they commit to reach by setting the policy rate. The MP propagation mechanism is sketched as follows: a shock in the policy rate modifies the risk free rate and financial assets' returns, short-lived arbitrage opportunities appear, until they are exhausted in a new equilibrium. This

1 The standard reference is the representative agent paradigm outlined by Woodford (2003). 
causes fluctuations in real consumption and investment. Firstly, with the new rates the previous consumption path is no longer satisfying the optimality conditions of the rational expectation (RE) equilibrium, and to restore it will imply adjustments. Secondly, investors facing changes in the short and long rates will adjust investment expenditures. These two factors explain output fluctuations.

If financial markets are transparent and perfectly competitive, arbitrage in security prices across maturities takes place instantaneously. As the "return-to-maturity" interpretation of the rational expectations hypothesis asserts, the expected return from holding a long bond until maturity equals the expected return from rolling over short bonds up to the time the long bond matures. Since this interpretation might be too restrictive, the term premium is defined as the excess yield that investors pretend to be compensated for holding a long-term bond instead of a series of shorter-term bonds. The relationship among interest rates at different maturities is known as the term structure of interest rates and is used to discount future cash flows. Besides, there are bonds whose pay outs are in terms of consumption or indexed to inflation. The difference between these payouts and those of nominal bonds is known as inflation risk premiums or break-even inflation. As we gauge break-even inflation at specific time horizons, we obtain -analogously to the term structure interest rates- a term structure for break-even inflation. In particular, break inflation inferred from bonds is the natural "market" benchmark to assess whether inflation expectations are anchored at the target within the policy horizon (indeed, one would find similar inflation expectation figures from regular market surveys).

We build a dynamic stochastic general equilibrium (DSGE) model that belongs to the consumption capital asset pricing model (C-CAPM) class and approximate it up to third order to obtain time-varying risk premiums. We judge relevant to characterize the effects of various shocks in ${ }^{2}$ :

1) the term structure of interest rates;

2) risk premium for different bond maturities 3 ;

3) the term structure of break-even inflation; and,

4) real interest rates.

We believe that the correct assessment of how monetary policy works is eased by inspection of the effects of monetary shocks in these four objects because their fluctuations have feedbacks into the real economy that are scarcely studied in structural models. Perhaps this is due to technical complexities that involve dealings with non-linearities.

2 The traditional CAPM is static and investors maximize their expected utility in the mean returns - returns' variances space. In contrast, the C-CAPM assumes a representative household that lives forever and maximizes the expected present value of lifetime utility. Provided households are risk averse, financial assets work in practice as an insurance that covers the uncertainty of consumption states: assets will be sold (bought) when times are bad (good); as a result, consumption will be smoothed.

3 Low (high) risk premium will be reflected in assets whose returns co-vary negatively (positively) with expected consumption growth. We explore fluctuations of this covariance term along the business cycle. 
Active research is taking place in this area of macrofinance both in the academic and in several CBs because it provides a valuable tool for policy makers to interpret how these feedbacks spill over into the macroeconomy. In our view, the development of the DSGE model with financial assets is a necessary step towards the implementation of non-linear filtering techniques that are used for estimation. Methodologically, our model is close to De Paoli et al. (2007); nonetheless, we approximate the model up to third order. Indeed, other papers approach the solution of the model up to third order, notably Ravenna and Seppala (2006). However, the novelty is that we derive asset pricing relationships explicitly, so it becomes apparent the role of conditional skewness in explaining asset returns, risk premiums and break-even inflation.

The structure of this paper is as follows. The next section reviews in detail the literature on macrofinance and previous work focusing on the Chilean economy. Section 3 presents a simple model, while Section 4 derives a third order approximation for relevant asset pricing relationships. Section 5 discusses the calibration chosen and reports results. Section 6 concludes.

\section{A LITERATURE REVIEW}

\subsection{Introducing financial assets into macro models}

Mehra and Prescott (1985) highlighted that a model variation of Lucas's (1978) pure exchange model is unable, under reasonable parameterization, to reproduce large mean returns on equity (about seven percent yearly from 1889 to 1978) and at the same time low risk free rates. The setting is a simple endowment economy, where consumption growth rate is an exogenous two-state Markov process (to take into account the fact that consumption is non-stationary). That puzzle prompted the literature to set models with a unifying framework capable of bringing predictions closer to the data. In so doing, common borders between macroeconomics and finance have become quite thin ${ }^{4}$.

For the sake of exposition, notice that there is a primary dissensus in approaching the puzzle. On the one hand, some authors believe on full asset market completeness, where gains from arbitrage are exhausted. On the other hand, James Tobin and followers, sustain that asset markets are segmented. The conclusions will dramatically differ: the former approach will conclude that risk premium or break-even inflation may be temporarily non-zero, while the second one will predict that because of market segmentation these can be non-zero forever.

Within the literature that assumes no arbitrage in asset markets we find: (i) highly stylized models that have affine structure for interest rates (i.e. unobserved components) and others that combine this assumption with a reduced form structure that describes

4 Campbell (1999) is a comprehensive survey. Moreover, there are several textbooks that shed light on financial macroeconomics at an introductory level. Campbell et al. (1997) and Cochrane (2005) are classics. They cover several asset pricing theories and summarize the empirical evidence. Wickens (2008, Ch. 10 and 11) introduces asset pricing theories and develops a simple DSGE model with assets. 
the economy (IS curve, Phillips curve) and (ii) macro or DSGE models derived from first principles with limited size in order to concentrate on assets.

\subsubsection{Macro models with segmented asset markets}

This subsection presents papers based on Tobin's idea: asset markets are incomplete and as a result returns will differ even if there is partial arbitrage because of asset market segmentation. Hence, risk premiums are exogenously determined and constant. Other authors obtain similar outcomes by assuming agents heterogeneity, which prevents full arbitrage, as Andrés et al. (2004).

Marzo et al. (2009) provide empirical evidence that suggests that the term structure of interest rates is an integral part of the monetary transmission mechanism. They construct a monetary business cycle model with some additions to get a timevarying term structure of interest rates. In particular, they assume that bond market segmentation works through the adjustment costs for bond holding changes and that there are transactions costs between money and bonds. The calibrated model replicates main stylized facts concerning the relation between output fluctuations and the yield spread: cor(yields spread,$\left.g d p_{t}\right)<0$, cor(yields spread,$\left.\Delta E_{t}\left(g d p_{t+j}\right)\right)>0$ and $\operatorname{cor}($ term premiums $\left._{t}, E_{t}\left(g d p_{t+j}\right)\right)<0$, where $g d p_{t}$ is the log of the Gross Domestic Product.

Zagaglia (2009a) estimates Marzo's et al. (2009) model with data on the Euro area, whereas Zagaglia (2009b) examines its forecasting performance. Zagaglia shows that adding money demand in the consumer decision problem as well as adding bond supplies helps explaining long-term interest rates fluctuations. The findings suggest that the feedback of bond yields on the macroeconomy gives rise to superior in-sample and out-of-sample forecasts for output, inflation and bond yields. This is robust to various univariate and multivariate accuracy measures.

\subsubsection{Macro models with affine asset pricing}

The main goal of affine asset pricing models is to explain the term structure of interest rates and by doing so to price fixed-income securities. This subsection reviews these models, especially those that combine the term structure of interest rates either with a vector autoregression (VAR) or with a model with some stylized structure, say the Phillips curve, an IS curve and a monetary policy rule. Affine models are parsimonious, flexible (because simple laws of motions capture common factors movement in interest rates and the term structure), and are suitable for forecasting. The disadvantage is that shocks to the term structure do not have a feedback into the economy and that changes in factors are difficult to interpret.

Ang and Piazzesi (2003) is one of the first attempts to merge affine models into linear models such as VARs, and estimate the whole model's parameters using full information methods. Bekaert et al. (2005) build a standard New-Keynesian (NK) model with a no-arbitrage affine term structure model and estimate it with generalized method of moments (GMM). The hybrid model is fed with unobservable processes for the inflation target and the natural rate of output which is filtered from macro and term structure data. They describe the responses of the entire term structure to various 
shocks. Moreover, the variance decomposition suggests that the inflation target shock is the main driver in the variation of the level factor, while monetary policy shocks dominate the variation in the slope and curvature factors. Emiris (2006) extends Smets and Wouters (2005)'s model with the US yield curve, derives bond pricing formulae and the implied risk premium for long term bonds. The findings suggest that if the researcher pretends to match the average 10-year term premium to the data, estimates of risk aversion and habit consumption must rise slightly. An increase in the term premium is achieved by a drop in the monetary policy parameter that governs the aggressiveness of the monetary policy rule. More smoothing in the MP conduct reinforces the covariance between the marginal rate of substitution of consumption and bond prices, turns positive the contribution of the inflation premium and drives the term premium up. The conclusion is that the interactions of inflation persistency with nominal rigidities are key factors for explaining the success in reconciling the macro model with the yield curve data.

Hoerdahl and Tristani's (2007) model is similar to Bekaert et al. (2005); their focus is on estimating the size and dynamics of inflation risk premiums in the Euro area after 1999. Employing both nominal and index-linked yields data, they find that on average term premium reflects predominantly real risks. Furthermore, inflation risk premium is close to zero, but occasionally subject to statistically significant fluctuations between 2004 and 2006.

Other studies remarked that non-linearities must be taken into account in the design of this kind of hybrid models. For example, Ang and Chen (2002) document that (conditional) correlations between single U.S. stocks and the aggregate U.S. stock market index are asymmetric and non-linear (i.e., greater (smaller) for downside (upside) moves) $)^{5}$. A similar message emerges for bond yields ${ }^{6}$. This evidence motivates the regime switching assumption in otherwise a standard affine term structure model. Ang et al. (2009) estimate the effect of shifts in monetary policy using the term structure of interest rates. They build on a no-arbitrage model where the short nominal rate is determined according to a Taylor (1993) rule with time-varying coefficients. Then, they calculate the mean and the sequence of policy reaction parameters, both for inflation and output. Regarding the latter, the average estimate is relatively stable, 0.4 . In contrast, the model suggests that inflation loadings have changed over the last 50 years: it ranges from close to zero in 2003 to 2.4 in 1983 . These swings in policy

5 Ang and Chen (2002) find that conditional on the downside, there is evidence of departure from normality in high frequency data and that conditional asymmetric correlations are fundamentally different from other measures of asymmetries (skewness and coskewness). Several empirical regularities are established: (i) small stocks, value stocks, and past loser stocks have more asymmetric movements; (ii) given a size, stocks with lower betas have greater correlation asymmetries; and (iii) no relationship between leverage and correlation asymmetries is found in the data. Models with regime switching do a better job at capturing correlation asymmetries.

6 Balfoussia and Wickens (2007) assume that the joint distribution of excess US bond returns of different maturity and the observable fundamental macroeconomic factors follow a multivariate GARCH process with conditional covariances in the mean to capture term premiums (this is essential if no-arbitrage supposedly holds). Primary risks are: (i) nominal (at all maturities) due to inflation and (ii) real as consumption growth fluctuates. The model does a better job explaining short than long maturities. 
concerns with respect to inflation lead to fluctuations in long-term bonds yields and term spreads ${ }^{7}$.

\subsubsection{Structural macro models}

In this section we review structural models that belong to the C-CAPM class. These models provide general asset price kernels that are function of state variables (expected growth of consumption, dividends, etc.) that serve to price any asset ${ }^{8}$.

In view of the result of Mehra and Prescott (1985), Campbell and Cochrane (1999) present a consumption-based model which is quite successful in solving the short- and long-run equity premium puzzles ${ }^{9}$. They suggest a modification of preferences: utility increases if consumption is in excess an external habit. The surplus consumption ratio, $s_{t}$, follows a heteroskedastic AR(1) process, so habit varies slowly. In bad times, when consumption is close to habit, risk aversion (locally) increases. The results suggest that habit formation is not enough for replicating joint macro and financial variables' moments because the expected value of the risk-free rate is larger than in the data. To fix this, they include heteroskedasticity via the sensitivity function $\lambda\left(s_{t}\right)$, i.e., $\sigma\left(s_{t}\right)=\lambda\left(s_{t}\right) \sigma$, which forces the risk-free rate to be a constant, while generating a time-varying countercyclical risk premium (and the Sharpe ratio). To make the riskfree rate constant necessitates that $\lambda^{\prime}\left(s_{t}\right)>0$, meaning that the deeper recession, the higher the uncertainty and higher the precautionary savings. Campbell and Cochrane (2000) simulate more carefully Campbell and Cochrane's model and reproduce timevarying expected returns, tracked by the dividend-price ratio. Lettau and Uhlig (2000) also include habit in consumption.

Overall, the literature that includes habits such as Campbell and Cochrane's (1999) study, generate risk premiums that are too small in orders of magnitude with respect to the data -roughly one basis point. To improve its predictions Wachter (2006) extends the model in two dimensions: (i) adds a feedback from surplus consumption to the risk-free rate ${ }^{10}$, and (ii) introduces an exogenous process for inflation. Key to get a reasonable in-sample fit of the model is the calibration of the preference parameter. The model nicely reproduces moments of bond returns as found in the US postwar data, and explains the time-series variation in short- and long-term bond yields.

So far, we have covered models with consumption endowment ${ }^{11}$. By including production and labor supply changes we enable consumers to exploit an additional channel for productivity shocks: the labor-consumption trade off to smooth out

In other words, a larger inflation loading implies higher short rates (yield spreads).

The generality of the asset pricing scheme justifies not devoting much attention to the specifics of the asset.

Campbell and Cochrane (1999) argue that the risk-free rate is constant in the data. Verdelhan (2010) is a two-country model that builds on habits to explain excess returns in currencies (delay overshooting in the real exchange rate). Two reasons explain the result: a risk free rate that is pro-cyclical and relative differences in local risk aversion of the typical agent.

10 The preference parameter endogenizes the tradeoff between the intertemporal substitution effect and the precautionary savings effect.

11 Strictly speaking, an endowment model yield results consistent with a linear technology; see Campbell and Cochrane 1999). Of course, ruling out variable labor supply. 
consumption. As in the early Real Business Cycle (RBC) literature, important questions are: Do results change if the labor supply is more elastic? Do widely documented labor market frictions play a role in affecting the risk premium variability?

Jermann (1998) is the first in examining asset returns in different versions of the typical one-sector RBC model with production. The paper explores in a novel way the fact that the consumer has an additional way to insure against an adverse shock, by adjusting the amount of time devoted to work. The author shows that habit formation in preferences and capital adjustment costs can explain the historical equity premium and the average risk-free return, while replicating the salient business cycle properties of the U.S. data. The model assumes that the stochastic discount factor and the asset returns are jointly lognormally distributed, which simplifies the solution of the loglinearized model.

Alvarez and Jermann (1999) examine a bond economy where the consumer can default her debt. They specify contract's conditions to induce payment as it is the consumer's best choice. The model generates large equity and long bonds premiums, whereas the risk free interest rate remains low.

Boldrin et al. (2001) extend the standard RBC model with two features: habit preferences and a two-sector technology with limited mobility of inputs across them. The model performs very well and matches first moments of the risk-free rate, equity premium, and Sharpe ratio on equity, while it outperforms substantially the standard RBC model.

Ravenna and Seppala (2006) examine the validity of the expectation hypothesis, derived from the theory concerning the information contained in the term structure. If the risk premium is zero or if is constant, the hypothesis is verified in its pure or regular versions, respectively. Empirically, the literature rejects both versions. For instance, Gallmeyer et al. (2005) rejects the expectation hypothesis in the context of affine models with two extensions: stochastic volatility of state variables and statedependent 'price of risk' in the stochastic discount factor. Ravenna and Seppala (2006) build a DSGE model and solve it with an approximation up to the third order. Relating to the previous result by Buraschi and Jiltsov (2005) that suggests that the time-variation of the inflation risk premium triggers deviations of the expectations hypothesis, the authors find the opposite: neither the MP shocks nor the inflation risk premium play such a role. However, smoothing in the MP rule does play a significant role (as well as in the consumption habit). In fact, it is true that in the absence of MP shocks, the inflation risk premium is much smaller and less volatile, but this does not imply a rejection of the expectation hypothesis (p. 26). Furthermore, the model is able to replicate much of the data: interest rates are procyclical, term spreads are countercyclical and the term spread has predictive power for future economic activity. A salient feature of the model's solution is the third order approximation, which reveals the pattern of time variation of inflation risk premium through the business cycle, which is not relevant for the rejection of the expectation hypothesis (just two shocks' volatilities are relevant: technology and preferences).

Ravenna and Seppala (2007) employs essentially the same model as Ravenna and Seppala (2006) who aim at examining with more detail the dynamic responses of the real interest rate, expected inflation and inflation risk premiums. Their findings are: 
(i) stochastic means of the inflation risk premiums are small and have low volatility, (ii) the short-maturity inflation risk premiums can be well approximated by a linear function of current inflation, (iii) the correlation between short-term real interest rates and expected inflation is negative and significant, and (iv) the short-term real interest rate is more volatile than expected inflation. They estimate a statistically significant Mundell-Tobin effect, which establishes that the gap between nominal and real interest rates widens when inflation is larger.

Uhlig (2007) includes asset price dynamics in a representative agent framework where the key features are the external habits in both consumption and labor, and real wage rigidities. He argues that a sizable risk aversion is not enough, to predict high Sharpe ratios (SR) or equity premiums. He points out that labor supply must lack flexibility, so he introduces real rigidities as in Blanchard and Galí (2007) ${ }^{12}$. Uhlig matches second moments of the data with an ad hoc weighting function that is evaluated with a grid on few dimensions and a simple search yields the optimum, in the same vein as GMM. He finds support of real rigidities because the model predicts an annual SR equal to 0.25 , quite close to the data, 0.3 , whereas the model version without real wage frictions yields an annual SR equal to 0.13 . He concludes that a combination of habits in both leisure and consumption and the addition of moderate real wage stickiness help matching the observed asset market as well as macro stylized facts.

Swanson (2007)'s note documents large swings in the long term interest rate. He suggests that this is because available measures of the term premium vary widely as they depend crucially on expectations of future short interest rates and inflation; both are hard to calculate with available econometric techniques. Rudebusch et al. (2007) motivates their paper based on a recent episode of monetary policy tightening that took place from June 2004 to June 2006: the Federal Reserve (FED) gradually raised the federal funds rate from one percent to $51 / 4$ percent and this had almost no effect on long-term interest rates. The referred disconnection seen in 10-year Treasury yields had no precedent in episodes of similar characteristics ${ }^{13}$. More insight on the issue comes from decomposing the long-term bond yield into: (i) an expectedrate component that reflects the anticipated average future short rate (corrected for maturity) and (ii) a term-premium component. So far, the evidence suggests that the latter component falls in recessions. They confront two interpretations. On the one hand, the practitioner's interpretation suggests that this low long rate exacerbated the housing/asset bubble that burst in 2008 (i.e. the tightening of the monetary policy seemed to have had little effect in preventing this episode). On the other hand, the IS curve in the typical NK model allow us to express output as the sum of the entire forward path of short-term rates, assigning no role to the term-premium component. Thus, the authors come up with a modified NK model where term premiums exert influence on the real economy. They calibrate the model due to complexities to take

12 The assumption is that the labor market does not clear at the efficient equilibrium because the steady state labor supply is fixed at some exogenously imposed level less than the one that would result in a frictionless economy.

13 Alan Greenspan, by then-Chairman of the FED, in a formal testimony before the Congress in February 2005, mentioned the broadly unanticipated behavior of world bond markets remains a conundrum. 
it to the data. To quantify the size and movements of the term premium, they estimate reduced-form models (factor models, VARs, etc.). Results suggest that higher future GDP growth is associated with a decline in term premium, which is not a robust prediction of the models reviewed so far.

A conclusion is that policy makers when confronted with substantial changes in term premiums should always try to determine the nature of the underlying shock. If that identification is feasible, say because a DSGE model is available, then the model may suggest relevant repercussions on macroeconomic variables of interest. On the contrary, if there is uncertainty on underlying shock, then reduced form models may be more advantageous to guide policy decisions.

Cochrane (2007) comments extensively on Rudebusch et al. (2007) and argues against the so-called "conundrum". He remarks that affine term structure models predict that: (i) long forwards should fall when the FED tightens (supposedly, higher policy rates today means lower inflation later, and thus lower nominal rates in the future); and (ii) all risk premiums should fall when the economy comes out of a recession. He concludes that there is a consensus on why the slope of the yield curve moves: the reasons are related to the monetary policy stance and the expected GDP growth. But, slope movements do not signal risk premiums, nor does covariance with monetary policy shocks generate a real risk premium. Term premiums are related with shocks in the level of the yield curve that are likely to be important in early stages of recessions or recoveries.

Rudebusch and Swanson (2008) examine the "bond premium puzzle" or the inability of standard theoretical models to replicate the nominal bond risk premium present in the data. They estimate a standard DSGE model and with simulations conclude that the term premium on long-term bonds is far too small and stable relative to the data. They follow the same estimation strategy as Uhlig (2007), with similar findings: more habits in consumption and labor market frictions allow the model to perform decently. However, it is disappointing that if they push the calibration to get closer to the data they distort the DSGE model's ability to fit other macroeconomic variables (real wage, etc.). Rudebusch and Swanson (2009) extend Rudebusch and Swanson's (2008) model with Epstein-Zin preferences, and obtain a large and variable term premium without compromising the model's ability to fit key macroeconomic variables. A technology shock drives inflation down and output up, which explains why the yield curve slopes upward. Moreover, the stochastic discount factor has endogenous conditional heteroskedasticity ${ }^{14}$. Finally, the assumption of long-run risks in the model relaxes the range of values for the quasi-CRRA coefficient.

De Paoli et al. (2007) examine bond and equity returns, the equity risk premium, and the behavior of the real and nominal term structure with a simple NK DSGE model approximated up to second order. They focus on quantifying the size of the risk premiums, the slope and level of the yield curve. The exercise takes into account several shocks one by one. Beginning with technology shocks solely, increasing the degree of real (nominal) rigidities raises (reduces) risk premiums, while for monetary

14 The result does not rely on (exogenous) autoregressive conditional heteroskedasticity (ARCH) in the data generating processes of shocks as in Campbell and Cochrane (2000). 
policy shocks, both real and nominal rigidities augment risk premiums. In general, first moments of asset returns depend crucially on the underlying specification of the model and on the shocks considered. Because the approximation does not go beyond the second order, they could not plot risk premiums impulse response functions (IRFs); this is done by De Paoli and Zabczyk (2009).

Hoerdahl et al. (2008) present a simple DSGE model for the U.S. with nominal rigidities and financial assets. Their attention is placed on stylized facts that have proven to be puzzling in this literature: sizeable term premiums, positive serial correlation in consumption growth as well as a positive slope of the term structure and roughly constant volatility of bond yields along the term structure. The performance of the calibrated model is evaluated in terms of unconditional moments of macro variables as well as the yield curve ${ }^{15}$. The main conclusion is that all features of the model contribute to aforementioned results, since nested (simpler) models yield moments that are farther away from the data. The smoothing feature of the MP exacerbates non-neutrality of money in the short run, given other standard frictions (habit in consumption and nominal rigidities).

Moller Andreasen (2008) extends a standard DSGE model with three shocks that are non-stationary. The model reproduces the dynamics in the 10-year yield curve for the post-war US data as well as for other key macroeconomic variables. The introduction of non-stationary shocks has similar effects to long-run risks (see below).

De Graeve et al. (2009) adapt Emiris (2006) and estimate the model by optimizing the posterior likelihood of the (log-linear) version of model. They are able to distinguish among bonds yields which vary according to their maturities. They conclude that: (i) small-scale DSGE models fall short in explaining movements in term premiums; (ii) underlying shocks responsible of the "conundrum" are a demand shock and a MP shock (through the lens of the model) ${ }^{16}$, and (iii) main reason behind the two inflation hikes in the U.S. in the 70s was the expected vs. actual inflation gap increased. Overall, the model is able to explain up to 90 per cent of historical U.S. bond yields fluctuations, a remarkable result given the linear approximation.

Doh (2009) estimates a DSGE model with U.S. macro and term structure data based on an approximate nonlinear solution and evaluate the likelihood with a particle filter. The study finds that nominal rigidities are important for identifying macro shocks, which ultimately determine responses in the yield curve. In particular, nominal rigidities interact with the systematic component of monetary policy (interest rate and inflation target persistencies). Markup shocks explain changes in the slope of the yield, while shocks in the inflation target shift the level of the yield ${ }^{17}$.

The puzzling result is that the posterior distribution of the parameter that accounts for the nominal rigidity seems to be bi-modal, with mass concentrating in an area with high nominal rigidity (thus yielding best in-sample fit). However, the less likely

15 The model is approximated up to second order and the policy function is feed into asset pricing formulae.

16 This becomes clearer when comparing the movements of the yield curve during the 2004-2006 episode with previous ones.

17 This shift in the yield is larger if nominal rigidities are small. Real shocks affect more the yield when the nominal rigidities are high. 
mode is more consistent with inflation expectation surveys, macro variables and bond yields. These results highlight the danger of relying on linearized versions of the model to do inference.

Fernandez-Villaverde et al. (2009) innovates adding time-varying volatility as a determinant of the real interest rate at which emerging small open economies (SOE) borrow. They find that $\mathrm{ARCH}$ data generating processes for real borrowing rates are statistically meaningful once these specifications are taken to data for Argentina, Ecuador, Venezuela, and Brazil. The estimation is conducted with the Particle filter and Bayesian methods. They include this margin into a DSGE model of an otherwise standard SOE, calibrated to mimic moments of these countries. The appealing conclusion is that volatility triggers a fall in output, consumption, investment, hours worked, and a substantial change in the current account.

Amisano and Tristani (2009) build a simple DSGE model and estimate its term structure implications with nominal rigidities. The innovation is that they assume that the laws of motion of structural shocks are subject to stochastic regime shifts. Without going further in the order of approximation, they show that up to a second order, the switching regime mechanism generates time-varying risk premiums. The model is estimated using the particle filter on US macro and financial data. The results are supportive of the regime-switching: each regime is meaningful and residuals are heteroskedastic ${ }^{18}$.

The paper by Chib et al. (2010) is similar to Amisano and Tristani (2009), but is extended to accommodate multiple monetary policy and volatility regimes. These papers share the methodology and the data. The results characterize the stance of US monetary policy that seems to have been "more active" since 1995:Q2 and average term premium has fallen. Reasons that explain the volatility of the term spread in the two regimes differ relatively: while the term premium explains a significant portion in the less active 'first' regime, its relative importance has reduced in the 'second' regime. In addition, they find that volatility of the technology shock accounts for most of the volatility in the term premium.

There are two streams of the literature that are worth mentioning. A first stream breaks the need of a high (uniform) degree of risk aversion by assuming heterogeneous agents or agents' types (with different preferences and tolerance to risk, etc). The following papers belong to this literature: Guvenen (2009), De Graeve et al. (2008), Guvenen (2007), Guvenen (2005), Danthine et al. (2005), Danthine and Donaldson (2002). A second stream of the literature is based on long run risk, proposed by Bansal and Yaron (2004). The basic idea is that expected consumption and dividend growth rates contain a small long-run component in the mean. In addition, there is conditional volatility in consumption, which makes its uncertainty show clusters; consequently, risk premiums are time-varying. They parameterize Epstein-Zin preferences in such a way that agents prefer an early resolution of consumption uncertainty (rather than to wait and see), leading to a positive excess return explained by long-run risk.

18 It is worth mentioning that the estimation method needs a long sample to identify different regimes. 
A final technical comment is that the solution methods that papers often use work well in the case of small shocks (e.g. perturbation methods). If we consider the last financial crisis of 2008, for example, it is clear that the reviewed literature does not provide the best answer ${ }^{19}$.

In sum, we conclude that DSGE models are the current paradigm that provides a consistent framework to study the joint dynamics of macro and financial variables and their interaction. We summarized advantages and disadvantages of this approach. There are several reasons to justify our choice of a DSGE model: it presents inner consistency, it produces results that are not affected by the Lucas Critique and it is feasible to approximate it with a Taylor expansion up to any order.

\subsection{Our approach, summary of results and extensions for future agenda}

We follow the structural (DSGE) approach and build a model economy with a very small dimension, i.e. a closed economy model. The model is approximated up to third order to study potential channels by which real and nominal shocks affect both financial and macroeconomic variables and to characterize effects of e.g. various shocks to time-varying term and risk premiums.

The comparison of the yield curve that results from the model with a reference to Chilean bonds yields data reveals to be somehow inconsistent with the widely accepted view that Chile is a $\mathrm{SOE}^{20}$.

The agenda for future research has to consider several extensions, summarized in what follows. First, on the functional forms of preferences, it has been investigated that recursive preferences help to get better results. There is a nice discussion in De Graeve et al. (2008) that refers back to seminal papers by Epstein and Zin (1989) and Epstein and Zin (1991). Recursive preferences have been explored recently in the DSGE models literature (e.g. Rudebusch and Swanson (2009), Amisano and Tristani (2009), Chib et al. (2010)) yielding amplified variation of the term premium along with a good fit of macro variables, having marginal improvement of bond yields time series (Amisano and Tristani (2009)). Van Binsbergen et al. (2010) add to previous models an exogenous inflation process to help match inflation volatility but generates too small mean term premiums with the usual observables (macro data and nominal bond yields). Second, if we want to take the model data seriously, we should either try limited information methods (i.e. grid search, simulated GMM etc.) or full information with the likelihood computed via a non-linear filter (as suggested by Doh (2009)). However, there are some data coverage limitations for the case of bonds: data starts from September 2002. Third, adding real rigidities in the labor market as in Blanchard and Galí (2007) increase the risk premium since it breaks the labor optimization condition; however, this does not lead to substantial risk premiums increase.

19 Jermann and Quadrini (2009) address this issue.

20 We leave for future research this extension. We believe that maintaining the same set of assumptions, but extending the closed economy to a SOE will not change dramatically the results. Of course, the SOE model is an unavoidable choice if it is taken to the data. 


\subsection{Previous studies for Chile}

The goal of this section is to review how recent studies that include financial assets into more or less structural models, focus on Chile ${ }^{21}$. To set the stage, consider that the primary objective of the Central Bank of Chile $(\mathrm{CBCH})$ is "to safeguard the stability of the currency and to ensure the normal functioning of domestic and external payments". The MP implementation is via an inflation targeting regime that targets an inflation objective of 3 per cent within two years ${ }^{22}$.

Ochoa (2006) provides an economic interpretation of the drivers of unobserved factors that give rise to movements in the term structure of interest rates within an estimated continuous-time no-arbitrage affine model for Chile. He concludes that short and long yields' dynamics are mainly explained by the policy rate and its timevarying central trend, respectively. The author interprets actual movements in the term structure as the result of a change in the slope that occurs jointly with a change in the level of the yield (triggered by long-lived innovations which have persistent effects). However, a deeper interpretation is elusive because the model lacks structure.

Jervis (2007) reviews three theoretical frameworks and documents empirically break-even inflation taking into account the term structure of the Chilean bonds. First, she solves a closed-economy structural model with optimal MP, where expected inflation depends on state variables of the economy. Second, she examines a microfounded model with a representative consumer, where the temporal profile of consumption, savings and asset prices are endogenously determined. Third, she proposes an imperfect asset substitution model to study the liquidity premium and, the question is whether it is explained by the relative stock of indexed bonds vis-a-vis nominal bonds. The maturity premium is ignored.

From an empirical perspective, time series of the break-even inflation and its components are calculated and then compared with expected inflation measures from surveys. With this data, the author estimates the policy function of the structural model with maximum likelihood (ML) and GMM.

The main findings are the following. First, for a short run horizon (up to 2 years) the break-even inflation seems to be relevant and robust. Three alternative surveys reveal that the inflation risk premium ranges from $-0.1 \%$ to $-0.06 \%$ in a 12 -months

21 D'Acuña et al. (2009 describe how the secondary bonds market works in Chile and summarize stylized facts. In particular, they present typical agents involved, traded instruments and the trading mechanism. Despite arbitrage works remarkably well for interest rates negotiated in the stock exchange and in the interbank market, they conclude that there is an important degree of segmentation in the secondary market. Regulated private pension funds administrators (AFPs) have access to the stock exchange, while on-shore banks trade extensively by themselves and as intermediaries. Off-shore banks usually have limited role in accessing spot markets, which is not the case in the swap market.

22 An inflation targeting regime was put in place since early 1990s and evolved as Fuentes et al. (2003) described. Before 1999 the policy instruments was a real interest rate (coupled with bands for the nominal exchange rate), since 2000 bands were abandoned, while from 2001:Q3 the instrument was a nominal interest rate. In particular, during the period 2000-6, the $\mathrm{CBCH}$ has targeted an inflation rate between two and four percent within a 24 months horizon as well as full flexibility of exchange rates. Since 2007, the $\mathrm{CBCH}$ targets a three percent inflation rate with a tolerance range of $+/$ - one percent within the same horizon. 
horizon, whereas the premium rises to a range between $0.17 \%$ and $0.20 \%$ for a 24 months horizon. Besides, the inflation risk, which includes all risks premiums, ranges from $-0.5 \%$ to $0.5 \%$. Second, break-even inflation is larger when measured with bonds that have a shorter maturity because short non-indexed bonds are more liquid. Third, one can observe a substantial reduction of break-even inflations driven by sound MP through the use of the interest rate. In other words, there is evidence that inflation expectations have been successfully shaped by the $\mathrm{CBCH}$.

Larraín (2007) examines the relationship between inflation compensation and inflation expectations in Chile. Applying the present discounted value methodology, he decomposes the gap between unanticipated returns of nominal and inflation-linked bonds into news about expected inflation and premiums, using monthly yields for the period 2002-2006. The results suggest that premiums are time-varying and explain yield-differential movements. Specifically, premiums explain around $40 \%$ to $65 \%$ of the inflation-compensation return variance. In light of the international evidence, these values seem to be too large (cfr. e.g. Ang et al. (2008)). Besides, a general equilibrium asset-pricing model is built to derive more explicit relationships, which are estimated with a VAR model assuming that rational expectations hypothesis holds. The results indicate that inflation-expectations movements account for about 25 percent of the relative returns. In addition, although the estimated inflation risk premium is timevarying, its mean value and volatility are negligible.

Morales (2007) fits an unrestricted VAR(1) model for the Chilean economy extended with a dynamic Nelson-Siegel (DNS) model ${ }^{23}$. The econometric methodology closely follows Diebold and Li (2006), where observables are the policy rate, annualized inflation and output gap. He finds a significant response of the MP instrument to impulses of the yield curve factors. In addition, responses of the level and slope of the yield curve are documented when shocks to real activity and monetary policy take place.

Chumacero and Opazo (2008) provide a simple analytical framework to decompose break-even inflation. Estimates suggest that one and two years ahead, break-even inflations are strongly linked to inflation expectations, and such figures are not necessarily inconsistent with the inflation target pursued by the $\mathrm{CBCH}$-at least in the sample analyzed. In the case of break-even inflation one year ahead (1-1), figures like those of March-2008 require premiums (e.g., liquidity premiums) in the order of 100 basis points to be consistent with an inflation rate of $3 \%$ two years ahead. While break-even inflation in longer horizons, (5-5) is higher, the gap between the 5-5 breakeven inflation and the target is small compared to other economies.

Bernier and Alarcon (2009) remark that at the end of 2007 the observed difference between break-even inflation measured by bonds issued by the $\mathrm{CBCH}$ and break-even inflation measured by interest rate swaps turned systematically negative and increasing. Moreover, what is named as the swap spread, namely the difference between indexed bonds (i.e., bonds denominated in unidades de fomento or UFs for short) rates and equally denominated interest rate swaps at similar maturities, turned negative as

23 The model includes yields and macroeconomic variables and it is cast out in a state-space form and estimated with ML methods employing the Kalman Filter. 
well. The authors examine the reasons that may explain such pattern identifying both structural and short-run factors.

Ceballos and Saavedra (2009) estimate break even inflation for the case of Chile with monthly data from July 2004 to July 2009. The approach is partly structural, because the break even inflation is estimated separately from the log-linearized (three equation) DSGE model; therefore, by construction, there is no feedback from the risk premium towards the economy.

Alfaro (2009) discretizes the model by Nelson and Seigel (1987) and proposes the mapping to an affine-yield model where the bond's yield depends linearly on three factors. Long term interest rate and the term spread are the two observable factors, while the remaining one is unobserved. The model is employed to characterize the yield curve in Chile and is specifically tailored to understand movements in the short rate.

In sum, the literature that works with Chilean yields is abundant. The evidence is largely documented employing affine models of the term structure; however, the DSGE model may provide a deeper structural interpretation of the changes in the yield curve. Moreover, the model can take into account the (time varying) feedback of change in the yield curve on the macroeconomic variables.

\section{MODEL}

This section presents a C-CAPM based on the representative consumer paradigm. It has minimal structure to illustrate in which margins DSGE models are capable of generating endogenous responses of break-even inflation, term premiums and so on.

\subsection{Consumers}

There is a continuum of households that lie in the unit interval. The representative consumer $j$ solves a constrained intertemporal problem which involves maximizing her lifetime utility:

$$
U_{t}^{j} \equiv E_{t}\left[\sum_{h=t}^{\infty} \beta^{h-t} U_{h}^{j}\right]
$$

where $U_{h}^{j}$ is the period-to-period ${ }^{24}$ :

$$
U_{t}^{j}=\zeta_{t} \log \left(C_{t}^{j}-b C_{t-1}^{j}\right)+\chi_{M}\left(\frac{M_{t}^{j}}{P_{t}}\right)^{v}-\chi_{L}\left(\frac{L_{t}^{j}}{1+\chi}\right)^{1+\chi},
$$

24 To get tractability we use log preferences. We tried the usual CRRA utility and results do not change substantially. 
subject to the real consumer budget constraint (CBC) and the law of motion of capital. The former reads as follows:

$$
\begin{aligned}
\frac{M_{t}^{j}}{P_{t}}+ & \left(C_{t}^{j}+I_{t}^{j}\right)+\frac{V_{t}^{e q}}{P_{t}} \frac{S_{t}^{j}}{S_{t}}+\sum_{h=1}^{H} \frac{V_{h, t}^{b n}}{P_{t}} B_{h, t}^{n, j}+\sum_{h=1}^{H} V_{h, t}^{b r} B_{h, t}^{r, j} \leq \frac{M_{t-1}^{j}}{P_{t}} \\
& +w_{t}^{j} L_{t}^{j}+\frac{T_{t}^{j}}{P_{t}}-\frac{T X_{t}^{j}}{P_{t}}+\left(\left(r_{t}^{k}\right)^{j} u_{t}^{j} K_{t-1}^{j}-\Phi\left(u_{t}^{j}\right) K_{t-1}^{j}\right) \\
+ & \frac{\left(V_{t}^{e q}+\mathrm{Pr}_{t}^{j}\right)}{P_{t}} \frac{S_{t-1}^{j}}{S_{t-1}}+\sum_{h=1}^{H} V_{h-1, t}^{b n} B_{h, t-1}^{n, j}+\sum_{h=1}^{H} \frac{V_{h-1, t}^{b r}}{P_{t}} B_{h, t-1}^{r, j},
\end{aligned}
$$

where $C_{t}^{j}-b C_{t-1}^{j}, M_{t}^{j} / P_{t}, L_{t}^{j}$, are arguments in the utility function: private consumption relative to an internal habit level, real money balances and labor supply, respectively. In addition, $\zeta_{t}$ is an exogenous process that accounts for changes in preferences defined bellow. According to (2) the consumer draws resources from beginning of the period of real balances of money and bonds (savings), real labor income, net of transfers real income $\left(\frac{T_{t}^{j}}{P_{t}}-\frac{T X_{t}^{j}}{P_{t}}\right)$, capital and dividends $\operatorname{Pr}_{t}^{j}$ real income which are allocated to consumption, investment, capital leased to firms, and purchases of real and nominal bonds of different maturities ${ }^{25}$.

Notice that due to complete markets, $V_{h, t}^{b n} B_{h, t}^{n, j} \equiv E_{t}\left[Q^{b n}\left(s^{t+h}, s^{t}\right) B^{n, j}\left(s^{t+h}\right)\right]$ and similarly for real values. Further, $V_{0, t}^{b n} B_{1, t}^{n, j}=1 B_{1, t}^{n, j}\left(s^{t}\right)=B_{1, t}^{n, j}\left(s^{t}\right) . B_{h, t}^{n, j}$ and $B_{h, t}^{r, j}$ are zero-coupon bonds of maturities ranging from $h=1$ to $H$, with payout of one unit of cash and of one unit of real consumption, respectively. This implies that stocks and bonds holdings carried from the previous period are revalued at market prices at the start of the subsequent period. Technically, the agent optimizes on these dimensions, meaning that the portfolio is sold off at the beginning of the new period.

There is a friction in adjusting capital given by:

$$
\Phi\left(u_{t}^{j}\right) \equiv \frac{r^{k}}{\theta} \times\left\{\exp \left[\theta\left(u_{t}^{j}-1\right)\right]-1\right\}
$$

25 We abstract from distortionary taxes to simplify the analysis. 
where $u_{t}^{j}$ is the utilization rate of capital, $\theta$ is a scale parameter and $r^{k}$ is the steady state return on capital. The first order conditions (FOCs) are summarized in the following. The FOC w.r.t. consumption is:

$$
\Lambda_{t}=\zeta_{t}\left[C_{t}-b C_{t-1}\right]^{-1}-\beta b E_{t}\left[\zeta_{t+1}\left[C_{t+1}-b C_{t}\right]^{-1}\right] .
$$

The FOC w.r.t. $K_{t}, I_{t}$ and $u_{t}^{j}$ are:

$$
\begin{aligned}
& \Lambda_{t}=\Gamma_{t}-\Gamma_{t} \Psi\left(\frac{\varepsilon_{I, t} t_{t}^{j}}{K_{t-1}^{j}}-\delta\right), \\
& \Gamma_{t}=\beta E_{t}\left\{\begin{array}{c}
\Lambda_{t+1}\left[\left(r_{t+1}^{k}\right)^{j} u_{t+1}^{j}-\Phi\left(u_{t+1}^{j}\right)\right] \\
+\Gamma_{t+1}\left[(1-\delta)-\frac{1}{2} \Psi\left(\frac{\varepsilon_{t, t+1} I_{t+1}^{j}}{K_{t}^{j}}-\delta\right)^{2}+\Psi\left(\frac{\varepsilon_{t, t+1}^{I_{t+1}^{j}}}{K_{t}^{j}}-\delta\right) \frac{\varepsilon_{t, t+1}^{I_{t+1}^{j}}}{K_{t}^{j}}\right]
\end{array}\right\}, \\
& \left(r_{t}^{k}\right)^{j}=\Phi^{\prime}\left(u_{t}^{j}\right) .
\end{aligned}
$$

In general, any asset $i$ 's future payouts, $X^{i}$, will be recursively valued by the equilibrium pricing equation:

$$
P_{t}^{i} \equiv E_{t}\left[S D F_{t+1} \times X_{t+1}^{i}\right]
$$

where the stochastic discount factor is $S D F_{t+1} \equiv \frac{\beta \Lambda_{t+1}}{\Lambda_{t}}$ (independent of agent $j$ since asset markets are complete). In our specific model,

$$
\frac{V_{h, t}^{b n}}{P_{t}}=E_{t}\left[S D F_{t+1} \frac{V_{h-1, t+1}^{b n}}{P_{t+1}}\right], \forall h,
$$

and returns $\operatorname{are}^{26}$ :

$$
R_{h, t+1}^{n r}=\left(V_{h, t}^{b n}\right)^{-\frac{1}{n}},
$$

26 Note that the previous equation can be written in a way that is clearly seen that is an Euler equation: $1=E_{t}\left[S D F_{t+1} \frac{1}{\Pi_{t+1}} \frac{V_{h-1, t+1}^{b n}}{V_{h, t}^{b n}}\right]$. 
where $V_{h-1, t+1}^{b n}$ is the value of a nominal bond valued in period $t+1$ which has time to maturity equal to $h-1$. Assuming no arbitrage conditions, this value will equal the price of a bond that will be issued in $t+1$ with maturity $j-1$. The strong implication is that bond prices (and from them yields) can be defined recursively. Similarly, for real bonds:

$$
V_{h, t}^{b r}=E_{t}\left[S D F_{t+1} V_{h-1, t+1}^{b r}\right], \forall h,
$$

with a return:

$$
R_{h, t+1}^{b r}=\left(V_{h, t}^{b r}\right)^{-\frac{1}{h}}
$$

where $V_{h-1, t+1}^{b r}$ is the value of a real bond valued in period $t+1$ which has time to maturity equal to $h-1$. Finally, the real value of equity shares is:

$$
\frac{V_{t}^{e q}}{P_{t}}=E_{t}\left[S D F_{t+1}\left(\frac{V_{t+1}^{e q}+\mathrm{Pr}_{t+1}^{j}}{P_{t+1}}\right)\right] .
$$

Let $h=1$ in (9), then:

$$
\frac{1}{R_{1, t+1}^{b r}}=E_{t}\left[S D F_{t+1}\right]
$$

because $R_{1, t+1}^{b r}=1 / V_{1, t}^{b r}$. In words, the one-period risk free real interest rate is the reverse of the SDF. Analogously, the real return on one-period equity holdings is:

$$
R_{t+1}^{E q}=\left(\frac{V_{t+1}^{e q}+\mathrm{Pr}_{t+1}^{j}}{V_{t}^{e q}}\right) \frac{1}{\Pi_{t+1}} .
$$

\subsubsection{Optimal wage setting}

Denote by $L_{t}^{j}(h)$ the demand of firm $h$ of labor variety of type $j$, it is assumed that a limited substitution among labor captured by the following labor bundle definition:

$$
L_{t}^{j} \equiv\left[\int_{0}^{1} L_{t}^{j}(h)^{\frac{\theta_{w t}-1}{\theta_{w i}}} d h\right]^{\frac{\theta_{w, t}}{\theta_{w i t}-1}}
$$


where $\theta_{w, t}$ is the elasticity of substitution between labor varieties and follows a stochastic process that converges to the constant $\theta_{w}>1$ :

$$
\ln \theta_{w, t}=\left(1-\rho_{\theta_{w}}\right) \ln \theta_{w}+\rho_{\theta_{w}} \ln \theta_{w, t-1}+v_{\theta_{w}, t},
$$

where $\mathrm{v}_{\theta_{w, t}}$ is iid. distributed with mean zero and constant variance. It can be shown that the solution of the labor bundler problem yields firms $h$ 's labor demand of labor $j$ :

$$
L_{t}^{j}(h)=\left(\frac{W_{t}^{j}}{W_{t}}\right)^{-\theta_{w, t}} L_{t}(h),
$$

where $W_{t}^{j}$ and $W_{t}$ are the wages effectively paid to employee $j$ and economy-wide aggregate wage, respectively. In particular, $W_{t}$ is quoted by the bundler:

$$
W_{t}^{1-\theta_{w, t}}=\int_{0}^{1} W_{t}^{j}{ }^{1-\theta_{w, t}} d j .
$$

We assume the consumer sets the wage according to the Calvo wage rule Calvo (1983). It can be shown that the optimal wage set is:

$$
\left(\breve{w}_{t}^{j}\right)^{1+\chi \theta_{w, t}}=\mu_{W, t} \chi_{L} \frac{\tilde{W}_{t}^{1}}{\tilde{W}_{t}^{-2}},
$$

where:

$$
\begin{aligned}
& W_{t}^{1} \equiv\left(L_{t}^{j}\right)^{1+\chi}+\beta \alpha_{W} E_{t}\left[\Pi_{W, t+1}^{\theta_{w, t}(1+\chi)} W_{t+1}^{1}\right], \\
& W_{t}^{2} \equiv \Lambda_{t} L_{t}^{j} w_{t}+\beta \alpha_{W} E_{t}\left[\Pi_{W, t+1}^{\theta_{w, t}-1} W_{t+1}^{2}\right],
\end{aligned}
$$

and $\Pi_{W, t+1}=W_{t+1} / W_{t}$.

In addition, $\tilde{\mu}_{W, t} \equiv \mu_{W, t}+\varepsilon_{\mu_{W}, t}$ where $\varepsilon_{\mu_{w, t}}$ represents the wage mark-up shock, an innovation with mean zero and constant variance. Moreover, $\mu_{W, t} \equiv \frac{\theta_{w, t}}{\theta_{w, t}-1}$ is the desired mark up which evaluated at the steady state becomes $\mu_{W} \equiv \frac{\theta_{W}}{\theta_{W}-1}$. Recently, Smets and Wouters (2007) have suggested an exogenous law of motion for $\mu_{W, t}$ in terms of $\operatorname{ARMA}(1,1)$ processes:

$$
\ln \mu_{W, t}=\left(1-\rho_{\mu_{W}}\right) \ln \mu_{W}+\rho_{\mu_{W}} \ln \mu_{W, t-1}+v_{W, t}-\vartheta_{W} v_{W, t-1},
$$


where $\rho_{\mu_{W}}$ captures the persistence and $\vartheta_{W}$ the memory of wage mark-up shocks ${ }^{27}$. This has the advantage of being easier to identify $\mu_{W}$ in the estimation stage as opposed to the elasticity $\theta_{W}{ }^{28}$.

Equation (16) suggests that the wage index that would prevail in the economy is (note that the equation has been normalized by $W_{t}^{1-\theta_{w, t}}$ ):

$$
1=\alpha_{W} \Pi_{W, t}^{\theta_{w, t}-1}+\left(1-\alpha_{W}\right)\left(\breve{w}_{t}^{j}\right)^{1-\theta_{w, t}},
$$

and to pin down the wage inflation we add:

$$
w_{t} \equiv \frac{\Pi_{W, t}}{\prod_{P, t}} w_{t-1} .
$$

\subsection{Firms}

Each firm $h$ is fully specialized in the production of variety $h \in(0,1)$ and there is a continuum of producers of measure 1. First, firm $h$ solves an intratemporal problem at the beginning of each period. The firm's problem is to determine demands of labor and capital services such that the total cost is minimized, subject to a given technology provided by the production function:

$$
Y_{t}(h)=A_{t}\left(u_{t} K_{t-1}(h)\right)^{\alpha} L_{t}(h)^{1-\alpha}-F C(h),
$$

where $F C(h)$ is a non-negative fixed cost from operating the firm that is set so that steady state profits are zero. Note that in the productive process, relevant inputs are an aggregate of labor varieties along with capital services (both supplied by households). $A_{t}$ is an exogenous technology process defined below.

Optimality yields the usual condition:

$$
\frac{1-\alpha}{\alpha}=\frac{W_{t} L_{t}(h)}{R_{t}^{k} u_{t} K_{t-1}(h)},
$$

and optimal inputs' demands by the firm. The real marginal cost is written as:

$$
m c_{t}=\frac{1}{A_{t}} \frac{\left(r_{t}^{k}\right)^{\alpha}\left(w_{t}\right)^{1-\alpha}}{\alpha^{\alpha}(1-\alpha)^{1-\alpha}} .
$$

27 Chari et al. (2009) put into question the wage-markup shock because, this (reduced-form shock) that can be equally interpreted in at least two ways: as fluctuations in unions' bargaining power or as labor effort shocks.

28 Because aggregate data seem to be uninformative to infer the degree of substitution among labor varieties. 
Second, the monopolistic competitive firm -when setting its optimal price- solves an intertemporal problem where the present value of benefits is maximized. It can be shown that home intermediate producers that follow a Calvo price setting would spell (if they receive the signal, which arrives with probability $\phi$ ):

$$
\frac{\tilde{P}_{t}(z)}{P_{t}}=\frac{\varepsilon}{\varepsilon-1}\left(\frac{\mathcal{Z}_{1, t}}{\mathcal{Z}_{2, t}}\right),
$$

where:

$$
\begin{aligned}
& \mathcal{Z}_{1, t}=\Lambda_{t} M C_{t} C_{t}+\phi \beta E_{t}\left\{\left[\frac{\Pi_{t+1}}{\left(\Pi_{t}\right)^{\xi}(\bar{\Pi})^{1-\xi}}\right]^{\varepsilon} \mathcal{Z}_{1, t+1}\right\}, \\
& \mathcal{Z}_{2, t}=\Lambda_{t} T_{t} C_{t}+\phi \beta E_{t}\left\{\left[\frac{\Pi_{t+1}}{\left(\Pi_{t}\right)^{\xi}(\bar{\Pi})^{1-\xi}}\right]^{\varepsilon-1} \mathcal{Z}_{2, t+1}\right\} .
\end{aligned}
$$

Then, price dynamics are given by (recall the normalization is w.r.t. $P_{t}$ ):

$$
1=(1-\phi)\left(\frac{\varepsilon}{\varepsilon-1}\left(\frac{\mathcal{Z}_{1, t}}{\mathcal{Z}_{2, t}}\right)\right)^{1-\varepsilon}+\phi\left[\frac{\Pi_{t}}{\left(\Pi_{t-1}\right)^{\xi}(\bar{\Pi})^{1-\xi}}\right]^{\varepsilon-1} .
$$

\subsection{Policies}

A standard Taylor rule provides a notional rate in setting MP:

$$
R_{\text {rule }, t}=\left(\frac{\Pi_{t}}{\bar{\Pi}_{t}}\right)^{\psi_{\pi}}\left(\frac{Y_{t}}{Y}\right)^{\psi_{y}},
$$

where $\Psi_{\pi}>1$ according to the Taylor principle and $\Psi_{y}$ measures the sensitivity of the CB to deviations of output from its steady state. It is also standard to assume smoothing or lagged impact of current MP decisions:

$$
R_{t}=R_{t-1}^{\psi_{R}} R_{r u l e, t}^{1-\psi_{R}} \exp \left(\varepsilon_{m, t}\right),
$$

where $\Psi_{R}$ is a smoothing parameter and $\varepsilon_{m, t}$ is an iid. shock with mean zero and constant variance. In addition, we assume that the inflation target fluctuates according to an exogenous process: 


$$
\bar{\Pi}_{t}=\left(\bar{\Pi}_{t-1}\right)^{\rho_{\bar{\Pi}}}(\bar{\Pi})^{1-\rho_{\bar{\Pi}}} \exp \left(\varepsilon_{\bar{\Pi}, t}\right),
$$

with persistency $\rho_{\bar{\pi}}$ and where $\varepsilon_{\bar{\pi}, t}$ is an iid. shock with mean zero and constant variance $^{29}$.

Fiscal policy is highly simplified. The government is committed to a zero-deficit rule by altering either lump-sum taxes or transfers. Government expenditure is a share of GDP:

$$
G_{t}=\left(1-\frac{1}{g_{t}}\right) Y_{t}
$$

where $g_{t}$ follows an exogenous process defined bellow.

\subsection{Price and wage dispersions}

The price and wage relationships under Calvo wage and price setting yield the following objects:

$$
\begin{gathered}
\Delta_{t}=(1-\phi)\left(\frac{\varepsilon}{\varepsilon-1}\left(\frac{\mathcal{Z}_{1, t}}{\mathcal{Z}_{2, t}}\right)\right)^{-\varepsilon}+\phi\left[\frac{\Pi_{t}}{\Pi_{t-1}^{\xi}(\bar{\Pi})^{1-\xi}}\right]^{\varepsilon} \Delta_{t-1}, \\
\Delta_{W, t}=\left(1-\phi_{L}\right)\left(\frac{\varepsilon_{L} \bar{\zeta}}{\left(\varepsilon_{L}-1\right)} \frac{\mathcal{H}_{1, t}^{w}}{\mathcal{H}_{2, t}^{w}}\right)^{-\varepsilon_{L}}+\phi_{L}\left[\frac{\Pi_{t}}{\Pi_{t-1}^{\xi_{L}}(\bar{\Pi})^{1-\xi_{L}}}\right]^{\varepsilon_{L}} \Delta_{W, t-1},
\end{gathered}
$$

that measure the distortions that arise due to gaps between: (i) quoted prices and (constant) marginal costs and (ii) wages and the (constant) marginal rate of substitution.

The variables in the LHS are equal to one when the model is approximated up to first order, whereas they are (weakly) higher if it is approximated up to second order or higher.

\subsection{Equilibrium}

There is equilibrium in the input markets as well as in goods markets. Goods market clearance implies that the gross domestic product (GDP) is:

29 Notice that we drop the $t$ subindex for variables evaluated at the steady state in Appendix B. There is an exception in the notation for the varying inflation target, it converges to $\bar{\Pi}=1$. 


$$
Y_{t}=\Delta_{t}\left[C_{t}+I_{t}+\left(1-\frac{1}{g_{t}}\right) Y_{t}\right]+\Phi\left(u_{t}^{j}\right) K_{t-1}
$$

\subsection{Exogenous processes}

The stochastic exogenous processes are (preferences, technology and government spending):

$$
\begin{aligned}
& \ln \zeta_{t}=\left(1-\rho_{\zeta}\right) \ln \zeta+\rho_{\zeta} \ln \zeta_{t-1}+\varepsilon_{\zeta, t}, \\
& \ln A_{t}=\left(1-\rho_{a}\right) \ln A+\rho_{a} \ln A_{t-1}+\varepsilon_{a, t}, \\
& \ln g_{t}=\left(1-\rho_{g}\right) \ln g+\rho_{g} \ln g_{t-1}+\varepsilon_{g, t},
\end{aligned}
$$

where steady state assumptions are, $\zeta=A=1$ and $g=0.2$.

\section{ASSET EQUATIONS APPROXIMATED UP TO THE THIRD ORDER}

This section derives asset price relationships that are approximated up to the third order. The reader is referred to Appendix $C$ for details on the model's approximation.

Notice that in general we denote log-deviations from the steady state as. $x \equiv \log (X / \bar{X})$. In particular, the stochastic discount factor is $s d f_{t+1} \equiv \log \left(\frac{\Lambda_{t+1}}{\Lambda_{t}}\right)$. The third order approximation of Eq. (11) is:

$$
r_{1, t+1}^{b r} \simeq-E_{t}\left[s d f_{t+1}\right]-\frac{1}{2} V_{t}\left[s d f_{t+1}\right]-\frac{1}{3 !} S k_{t}\left[s d f_{t+1}\right]
$$

where $S k_{t}\left[s d f_{t+1}\right]=T^{-1} \sum_{t=1}^{T}\left(s d f_{t+1}-E_{t}\left[s d f_{t+1}\right]\right)^{3}$.

Employing Eq. (10) and Eq. (12), it can be shown that the equity risk can be approximated up to third order as:

$$
\begin{aligned}
E_{t}\left[r_{t+1}^{e q}\right] \simeq & -E_{t}\left[s d f_{t+1}\right]-\frac{1}{2} V_{t}\left[s d f_{t+1}\right]-\frac{1}{2} V_{t}\left[r_{t+1}^{e q}\right] \\
& -\operatorname{CoV}_{t}\left[s d f_{t+1}, r_{t+1}^{e q}\right]-\frac{1}{3 !} S k_{t}\left[s d f_{t+1}+r_{t+1}^{e q}\right]
\end{aligned}
$$


where we derived an expression for $S k_{t}\left[s d f_{t+1}+r_{t+1}^{e q}\right]$ in the Appendix A, that replaced in Eq. (31) yields:

$$
\begin{aligned}
E_{t}\left[r_{t+1}^{e q}\right] \simeq & -E_{t}\left[s d f_{t+1}\right]-\frac{1}{2} V_{t}\left[s d f_{t+1}\right]-\frac{1}{2} V_{t}\left[r_{t+1}^{e q}\right]-\operatorname{CoV}_{t}\left[s d f_{t+1}, r_{t+1}^{e q}\right] \\
& -\frac{1}{6} S k_{t}\left[s d f_{t+1}\right]-\frac{1}{6} S k_{t}\left[r_{t+1}^{e q}\right]+E_{t}\left[r_{t+1}^{e q}\right] E_{t}\left[\left(s d f_{t+1}\right)^{2}\right] \\
& +E_{t}\left[s d f_{t+1}\right] E_{t}\left[\left(r_{t+1}^{e q}\right)^{2}\right] .
\end{aligned}
$$

The equity risk premium results subtracting both sides of Eq. (31) and Eq. (30):

$$
\begin{aligned}
E_{t}\left[r_{t+1}^{e q}\right]-r_{1, t+1}^{b r} \simeq & -\frac{1}{2} V_{t}\left[r_{t+1}^{e q}\right]-\operatorname{CoV}_{t}\left[s d f_{t+1}, r_{t+1}^{e q}\right]-\frac{1}{6} S k_{t}\left[r_{t+1}^{e q}\right] \\
& +E_{t}\left[r_{t+1}^{e q}\right] E_{t}\left[\left(s d f_{t+1}\right)^{2}\right]+E_{t}\left[s d f_{t+1}\right] E_{t}\left[\left(r_{t+1}^{e q}\right)^{2}\right]
\end{aligned}
$$

The equity risk premium will be positive if equity returns are expected to be low when the stochastic discount factor is high, and vice versa. That is, if returns are low, when they are most wanted (i.e. when marginal utility is increasing), investors will ask for a premium to hold equities. In addition, increases in volatility in the stochastic discount factor and equity return will increase the magnitude of the equity premium.

Next, the real return at maturity $h$ is given by Eq. (8), but taking into account Eq. (11), it is equal to $R_{h, t+1}^{b r}=\left(S D F_{t+h}\right)^{-\frac{1}{h}}$. Approximating up to third order the previous equation yields:

$$
E_{t}\left[r_{h, t+1}^{b r}\right] \simeq-\frac{1}{h}\left(E_{t}\left[s d f_{t+h}\right]+\frac{1}{2} V_{t}\left[s d f_{t+h}\right]+\frac{1}{6} S k_{t}\left[s d f_{t+h}\right]\right),
$$

which allow us to calculate the real term premium:

$$
\begin{aligned}
E_{t}\left[r_{h, t+1}^{b r}\right]-E_{t}\left[r_{1, t+1}^{b r}\right] \simeq & E_{t}\left[s d f_{t+1}-\frac{s d f_{t+h}}{h}\right] \\
& +\frac{1}{2}\left[V_{t}\left[s d f_{t+1}\right]-V_{t}\left[\frac{s d f_{t+h}}{h}\right]\right] \\
& +\frac{1}{6}\left[S k_{t}\left[s d f_{t+1}\right]-S k_{t}\left[\frac{s d f_{t+h}}{h}\right]\right] .
\end{aligned}
$$


The real yield curve is upward (downward) sloping if the last two terms on the RHS are positive (negative). The interpretation of the differences in variances term in the RHS is as follows: if the growth rate of marginal utility is positively autocorrelated, such that the numerator rises faster than $h$, this would tend to generate a downward sloping yield curve. If a 'bad' shock is expected to be followed by other bad events, risk-averse investors appreciate locking-in today a given return in the future, and therefore longer-term bonds serve as a form of insurance. The differences in kurtosis term will capture the effect or differences in responses under a positive or negative shock.

Next, we approximate nominal bond returns with maturity $h, R_{h, t+1}^{b n}=\left(s d f_{t+h} / \Pi_{t+h}\right)^{-\frac{1}{h}}$, as

$$
E_{t}\left[r_{h, t+1}^{b n}\right] \simeq \frac{1}{h}\left[\begin{array}{c}
-E_{t}\left[s d f_{t+h}\right]+E_{t}\left[\pi_{t+h}\right] \\
-\frac{1}{2} V_{t}\left[s d f_{t+h}\right]+\frac{1}{2} V_{t}\left[\pi_{t+h}\right]-C_{t} V_{t}\left[s d f_{t+h}, \pi_{t+h}\right] \\
+\frac{1}{6} S k_{t}\left[\pi_{t+h}-s d f_{t+h}\right]
\end{array}\right]
$$

where $S k_{t}\left[\pi_{t+h}-s d f_{t+h}\right]$ is given by Eq. (35) in Appendix A. Then, the spot $(h=1)$ break-even inflation up to third order can be written as:

$$
\begin{aligned}
E_{t}\left(r_{1, t+1}^{b n}-r_{1, t+1}^{b r}\right) \simeq & E_{t}\left[\pi_{t+1}\right]+\frac{1}{2} V_{t}\left[\pi_{t+1}\right]-\operatorname{CoV}_{t}\left[s d f_{t+1}, \pi_{t+1}\right] \\
& +\frac{1}{6} S k_{t}\left[\pi_{t+1}\right]+E_{t}\left[s d f_{t+1}\right] E_{t}\left[\left(\pi_{t+1}\right)^{2}\right] \\
& +\left[E_{t}\left(s d f_{t+1}\right)\right]^{2} E_{t}\left[\pi_{t+1}\right] .
\end{aligned}
$$

An increase in consumption volatility that increases precautionary savings will therefore reduce both the expectation of the real and nominal interest rates by the same amount.

The nominal interest rate is also affected by:

(1) the steady-state inflation (zero).

(2) a Jensen's inequality term that will increase as the variability of inflation increases, thus increasing the premium.

(3) the covariance term measures the inflation risk premium: if inflation is high when the value of extra consumption is high (i.e. positive covariance), the risk premium is positive and lowers the break-even inflation.

(4) further terms on the right involve the conditional kurtosis on future inflation and volatilities of the future stochastic discount factor and inflation weighted by expected values. 


\section{RESULTS}

In this section we report results from the numerical simulation. We begin presenting the set of calibrated parameters. Then, we examine the model's fit regarding first and second moments of selected variables. We emphasize first moments of nominal and real bonds level yields at various maturities as well as slopes. Finally, impulse response functions illustrate effects of various fundamental shocks on bond level yields as well as on yield slopes.

Table 1 reports model's calibrated parameters, which are rather standard. Since we want to have as reference unconditional means of some yields, but at the same time abstracting as much a possible of particularities of the Chilean economy, we assume that the inflation target is zero inflation, so the real rate is also the nominal ${ }^{30}$. Consequently, the beta parameter is set to $(1.0417)^{-0.25}$, where $4.17 \%$ is the average of the policy rate in the sample 2001:Q3-2009:Q3. $\Psi$ measures adjustment costs of new investment to become productive, i.e., physical capital. The product elasticity of capital services is $\alpha$. Elasticities of substitutions of consumption (labor) varieties are consistent with markups on marginal costs (marginal rates of substitution between leisure and consumption) of $20 \%$. On average, nominal prices and wages are reset once a year, see Bils and Klenow (2004). The elasticity of labor supply is reasonable for Anglo-Saxon countries. The degree of habit in consumption amounts to $60 \%$ of past consumption. Price and wage indexation to past inflation weights 0,5 . The persistence of exogenous processes are estimated with data for Chile equation by equation. Variances' sizes are mainly borrowed from other studies.

\section{TABLE 1}

\section{PARAMETERIZATION}

\begin{tabular}{|l|l|l|}
\hline Parameters & Value & \\
\hline$\beta$ & $(1.0417)^{-0.25}$ & TPM sample mean 4.17\% (2001:3-2009:3) \\
$\delta$ & 0.025 & Depreciation rate, quarterly \\
$\theta$ & 1 & Shift parameter in the utilization function \\
$\Psi$ & 8 & Canzoneri et al. $(2007)$ \\
$\alpha$ & 0.24 & Share of capital in the prod. function \\
$\varepsilon\left(\theta_{W}\right)$ & 6 & Elasticity of subst. in goods (labor) varieties \\
$\mu_{p}\left(\mu_{W}\right)$ & 1.2 & Price (wage) markup \\
$\phi\left(\phi_{L}\right)$ & 0.75 & Calvo price prob. to reset prices (wages) \\
$x$ & 3 & Reverse of the Frisch elasticity \\
$b$ & 0.6 & Habit formation parameter \\
$\xi\left(\xi_{L}\right)$ & 0.5 & Past inflation indexation share prices \\
& & (wages) \\
\hline
\end{tabular}

30 It might seem controversial to take this decision in view of institutional features of the inflation targeting regime in place in Chile. Simplification justifies this choice (analogous to the closed economy assumption employed when we set the model). Provided inflation target is constant and expectations are anchored, the model would predict that unconditional means of nominal and real yields (with identical maturity) will differ in the inflation target. 


\begin{tabular}{|l|l|l|}
\hline \multicolumn{3}{|c|}{ AR(1) processes and stochastic shocks } \\
\hline$\rho_{a}$ & 0.8 & persistence productivity shock \\
$\rho_{g}$ & 0.87 & persistence government share shock \\
$\rho_{\zeta}$ & 0.5 & persistence shock in preferences \\
$\rho_{1}$ & 0.5 & persistence investment shock \\
$\rho_{m}$ & 0.824 & persistence in MP shock \\
$\rho_{\bar{\Pi}}$ & 0.15 & persistence in MP target shock \\
$\sigma_{\varepsilon_{a}}$ & 0.009 & Jermann (1998) \\
$\sigma_{\varepsilon_{g}}$ & 0.0009 & Canzoneri et al. (2007) \\
$\sigma_{\varepsilon_{m}}$ & 0.00245 & \\
$\operatorname{cov}\left(\varepsilon_{a}, \varepsilon_{m}\right)$ & 0.00000267 & \\
$\sigma_{\varepsilon_{\zeta}}$ & 0.008 & \\
$\sigma_{\varepsilon_{1}}$ & 0.008 & \\
$\sigma_{\varepsilon_{\bar{\Pi}}}$ & 0.0009 & \\
\hline
\end{tabular}

\subsection{Model's fit}

In this section, we provide evidence on the model's goodness-of-fit conditional on the calibration. While first moments are largely determined by the steady state solution, second moments depends on the complexity of the structural model and on shocks sizes. We report standard deviations of model's main variables in Table $2^{31}$. As one would expect, as the shocks size increases, standard deviations of endogenous variables increase as well. We assumed that doubling the shocks' volatility (i.e., $2 x$ ) does not yield to a two-fold standard deviation of endogenous variables.

\section{TABLE 2}

EFFECTS OF INCREASING SHOCKS' VOLATILITIES ON SD OF ENDOGENOUS MACRO VARIABLES (PERCENTAGE POINTS)

\begin{tabular}{|l|c|c|c|}
\hline Shocks variances & $1 \mathrm{x}$ & $2 \mathrm{x}$ & $3 \mathrm{x}$ \\
\hline Consumption & 4.69 & 6.63 & 11.48 \\
Investment & 8.29 & 11.73 & 20.31 \\
GDP & 13.16 & 18.61 & 32.24 \\
Real wage & 2.25 & 3.18 & 5.5 \\
CPI inflation & 0.28 & 0.4 & 0.69 \\
Real interest rate & 0.08 & 0.12 & 0.21 \\
Real Return Equity & 6.12 & 8.65 & 14.98 \\
Return on real bond & 0.77 & 1.1 & 1.9 \\
Return on nominal bond & 0.8 & 1.13 & 1.96 \\
Equity risk premium & 5.71 & 8.08 & 13.99 \\
Inflation risk premium & 0.24 & 0.34 & 0.59 \\
\hline
\end{tabular}

Note: all shocks included, approximation order is 2.

31 We apply second (and not third) order of approximation for the sake of saving computing time since it is enough in order to illustrate the point. 


\section{TABLE 3}

EFFECTS OF INCREASING SHOCKS' VOLATILITIES ON THE MEAN OF FINANCIAL VARIABLES

\begin{tabular}{|c|rrr|c|ccc|}
\hline Shock variances & $1 \mathrm{x}$ & $2 \mathrm{x}$ & $3 \mathrm{x}$ & & $1 \mathrm{x}$ & $2 \mathrm{x}$ & $3 \mathrm{x}$ \\
\hline Nom. level returns & & & & Real level returns & & & \\
\hline RN1 & 4.114 & 4.122 & 4.152 & RR1 & 4.105 & 4.103 & 4.098 \\
RN4 & 4.125 & 4.143 & 4.218 & RR4 & 4.129 & 4.152 & 4.244 \\
RN8 & 4.114 & 4.121 & 4.151 & RR8 & 4.116 & 4.125 & 4.161 \\
RN20 & 4.107 & 4.108 & 4.11 & RR20 & 4.108 & 4.109 & 4.115 \\
RN40 & 4.107 & 4.107 & 4.107 & RR40 & 4.108 & 4.107 & 4.108 \\
& & & & Req & 13.58 & 18.9 & 40.18 \\
\hline Nom. yield slopes & & & & Real yield slopes & & & \\
\hline RN4-RN1 & 0.011 & 0.022 & 0.066 & RR4-RR1 & 0.024 & 0.049 & 0.146 \\
RN8-RN1 & -0.000 & -0.001 & -0.002 & RR8-RR1 & 0.011 & 0.021 & 0.064 \\
RN20-RN1 & -0.007 & -0.014 & -0.042 & RR20-RR1 & 0.003 & 0.006 & 0.017 \\
RN40-RN1 & -0.008 & -0.015 & -0.045 & RR40-RR1 & 0.002 & 0.004 & 0.011 \\
& & & & Req-RR1 & 9.47 & 14.8 & 36.08 \\
\hline
\end{tabular}

Note: order of approximation is 2

\section{TABLE 4}

\section{INCREASING THE ORDER OF APPROXIMATION PROVIDES A MORE CURVED YIELD}

\begin{tabular}{|l|ccc|l|lcc|}
\hline Order of approx. & 1 & 2 & 3 & & 1 & 2 & 3 \\
\hline Nom. level returns & & & & Real level returns & & & \\
\hline RN1 & 4.106 & 4.114 & 4.022 & RR1 & 4.106 & 4.105 & 4.026 \\
RN4 & 4.106 & 4.125 & 4.161 & RR4 & 4.106 & 4.129 & 4.159 \\
RN8 & 4.106 & 4.114 & 4.127 & RR8 & 4.106 & 4.116 & 4.126 \\
RN20 & 4.106 & 4.107 & 4.111 & RR20 & 4.106 & 4.108 & 4.110 \\
RN40 & 4.106 & 4.107 & 4.108 & RR40 & 4.106 & 4.107 & 4.108 \\
& & & & Req & 8.254 & 13.58 & 16.06 \\
\hline Nom. yield slopes & & & & Real yield slopes & & & \\
\hline RN4-RN1 & 0 & 0.011 & 0.139 & RR4-RR1 & 0 & 0.024 & 0.133 \\
RN8-RN1 & 0 & -0.000 & 0.105 & RR8-RR1 & 0 & 0.011 & 0.099 \\
RN20-RN1 & 0 & -0.007 & 0.089 & RR20-RR1 & 0 & 0.003 & 0.084 \\
RN40-RN1 & 0 & -0.008 & 0.086 & RR40-RR1 & 0 & 0.002 & 0.082 \\
& & & & Req-RR1 & 4.149 & 9.47 & 12.03 \\
\hline
\end{tabular}

Table 2 also suggests that there exist a trade off between getting a better fit of absolute term premiums (break-even inflation, etc.) and macro variables just by increasing shocks volatilities ${ }^{32}$.

32 Not surprisingly, relative second moments seem to be constant, e.g., $\operatorname{sd}(C) / \operatorname{sd}(Y)$ are $0.047 / 0.1316=0.357$, 0.355 and 0.357, respectively (Rudebusch-and Swanson (2008)). 


\subsection{Model's implied yield curve}

Tables 3 and 4 report yields levels and slopes for a number of common maturities of Chilean bonds. These tables are divided in two main blocks including: (i) nominal yields denoted as "RN $j$ " for nominal bond yields with maturity $j$ quarters and (ii) real yields, where different returns on real bonds are denoted as "RR $j$ " (i.e. bonds indexed to UF) with $j$ quarters to maturity as well as the real return on equity denoted by "Req". On the bottom part of these tables we report nominal and real yield slopes of various maturities.

In particular, Table 3 was calculated including all shocks with a model solution up to second order. For the sake of easing the interpretation of Table 3's content, assume that for some reason risk premium is kept constant (i.e. we stick to second order approximation), then we ask what is the effect on mean returns if variances of all shocks double or become three-fold the original values. The real bonds returns with the shortest maturity diminish while nominal bonds returns increase, and breakeven inflation goes up. However, the returns on nominal and real bonds increase with volatility for horizons from 4 onwards and the effect on break-even inflation seems is no longer clear cut.

Table 4 answers the following question: does a higher order approximation affect the size of the term premium? Because of the certainty equivalence, notice that with a first order approximation the term premium is zero and the equity premium excess return is positive. However, real term premiums computed with a second and third order approximation are positive, whereas results are mixed for nominal term premiums. It seems to be the case that under 2 nd order approximation, longer nominal bonds have negative slopes, or in other words, they work as insurance (an effect that is exacerbated when the volatilities of shocks increase by $2 \mathrm{x}$ or $3 \mathrm{x}$, see Table 3 ), but for an approximation up to third order the slope sign is not robust, slopes are positive.

Of course, changes in slopes are consistent with the fact that higher order approximation modifies the mean return of bonds at different maturities (which becomes apparent by comparing columns). The stark case comes out from considering a first order approximation (column 2), where all returns are the same and risk premium in constant and equal to zero (certainty equivalence). When we move to a second order approximation (column 3) we find some curvature, notably for the return on equity which grows by more than $50 \%$. Up to third order (column 4), we observe even more curvature on the yields of different bonds and, notably, this return on equity roughly doubles the one under first order approximation.

Figure 1 plots yields of bonds under different approximation orders. An extreme case takes place with first order approximation: yields at different maturities are constant, at a lower level than the policy rate, $4.17 \%$, due to the constant and zero risk premium (with brown squares and green triangles markers, respectively). When going up to a second order approximation, the figure suggests that yields vary according to the maturity: the higher nominal yield is of a bond of one year of maturity, while bonds that mature in the long run pay less. Up to (second) third order we observe more curvature; level yields are indicated as (blue diamond) grey crosses. The main message is that for shorter maturities, higher order of approximation offers more curvature term 


\section{FIGURE 1}

REAL (UPPER GRAPH) AND NOMINAL (BOTTOM GRAPH) BOND YIELDS (\%)

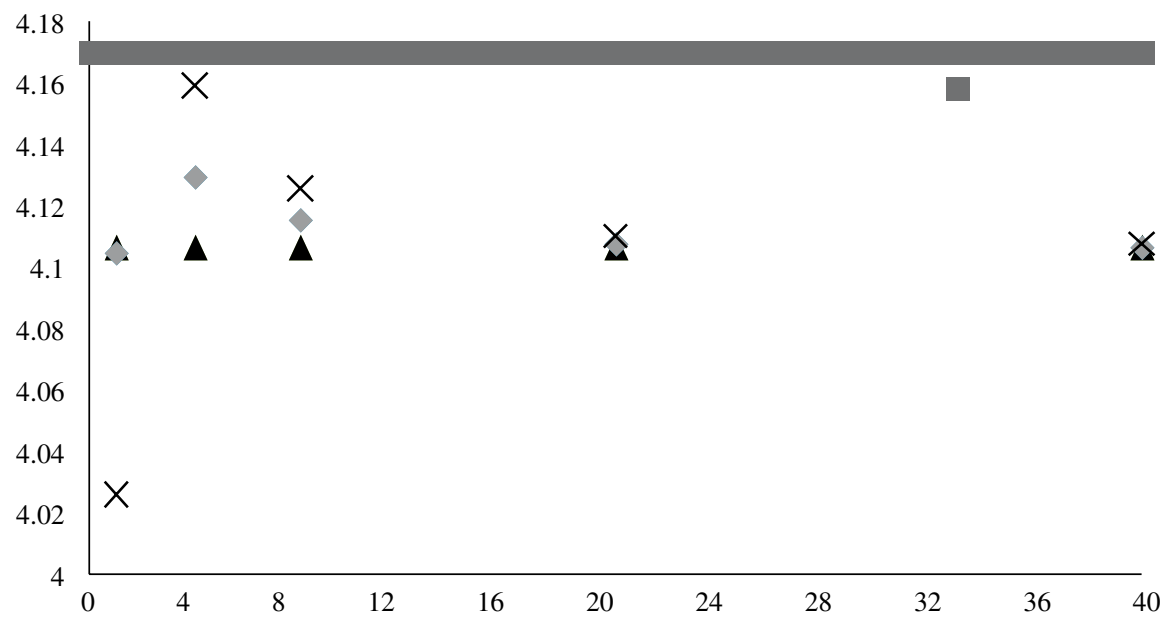

TPM $\Delta$ Real Bonds (1) $\diamond$ Real Bonds (2) $\quad \times$ Real Bonds (3)

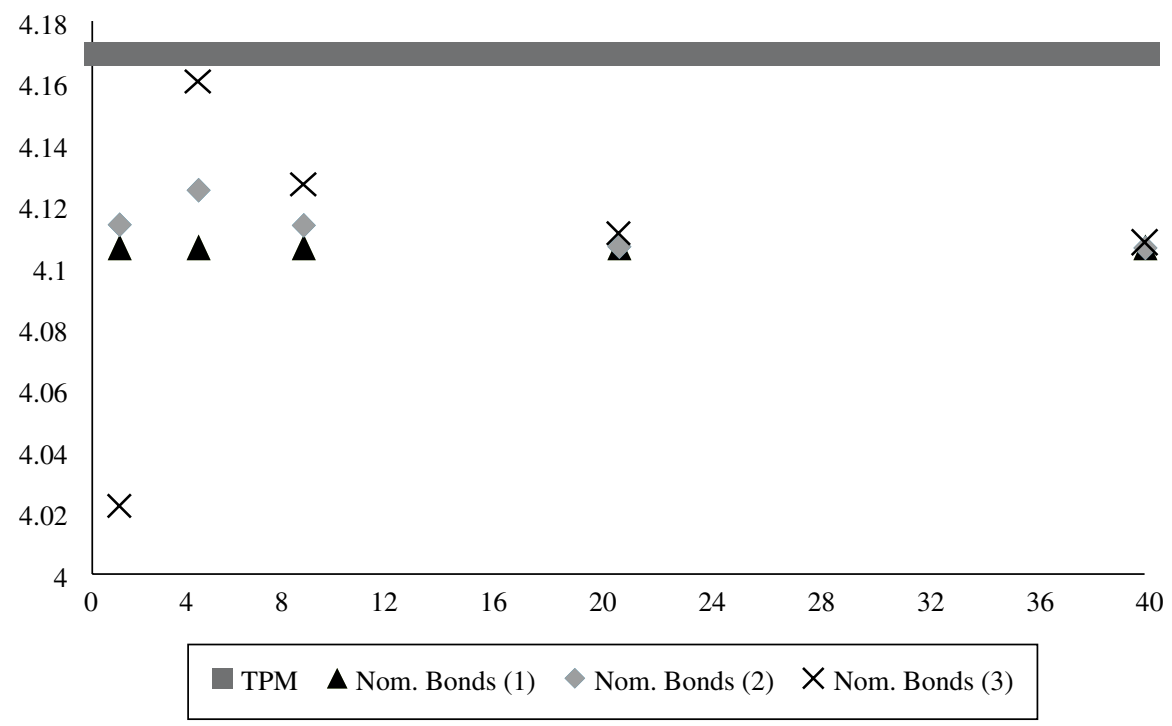

Note: under different orders of approximation (in brackets) 
premium, equity premium and break-even inflation (also they are time-varying as we will see shortly). This curvature effect is less important for longer maturities as the dots tend to concentrate on a smaller area. Of course, the fact that we have discrete number of maturities is because we take the maturities of bonds issued which have secondary market in Chile.

\subsection{Impulse responses}

In this section we present impulse response functions for all shocks of size $1 \%{ }^{33}$. Bearing in mind that the model's policy function is approximated up to the third order, it is the case that the non-stochastic steady state is not equal to the unconditional mean. The difference between these fixed points is that in the former case the second moments of shocks are zero, whereas for the latter they matter for the solution ${ }^{34}$. The IRFs reported below measure deviations from the non-stochastic steady state.

In Figure 2 we observe that most relevant shocks are technology, inflation target and monetary policy. In general, the former decreases the yield for all maturities (relatively more for long run bonds) with a notorious hump-shape for short bonds. The effect of a positive inflation target shock depresses real yields in the short run and then the effect is undone. Monetary policy shocks reveal how the propagation channel seems to work: they alter the short part of the yield curve more than the large part: the increase in the policy rates impacts more in the short run real bond with an effect that last about 1.5 to 2 years. Figure 3 displays a similar pattern for long real bonds and short nominal bonds, while Figure 4 completes with long nominal bonds. Comparing these figures we find that nominal spot returns respond by more on impact for productivity shocks, while for other shocks differences are seem to be smaller. Real and nominal bonds with longer maturities present little difference in responses. This suggests that the models will provide predictions of tiny variations in break-even inflation.

33 In linear models, IRFs of endogenous variables add up easily. Hence, it is standard to normalize shocks' size to $1 \%$.

34 For a discussion on the derivation of IRFs for non-linear univariate time series see Potter (2000), whereas for their generalization to a multivariate setting see Koop et al. (1996). 


\section{FIGURE 2}

REAL YIELDS OF REAL BOND, RESPONSES TO VARIOUS SHOCKS

Real return spot

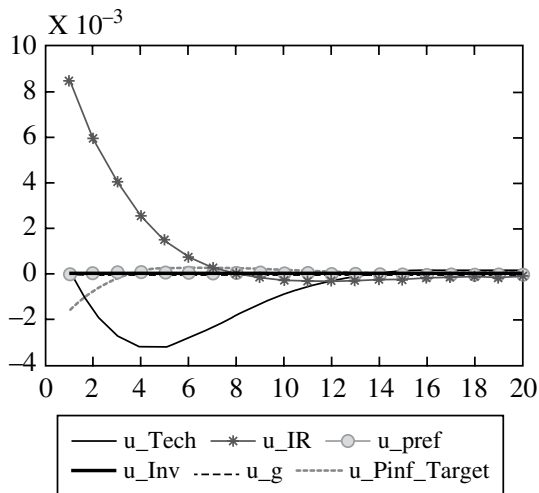

Real return ( 2 year bonds)

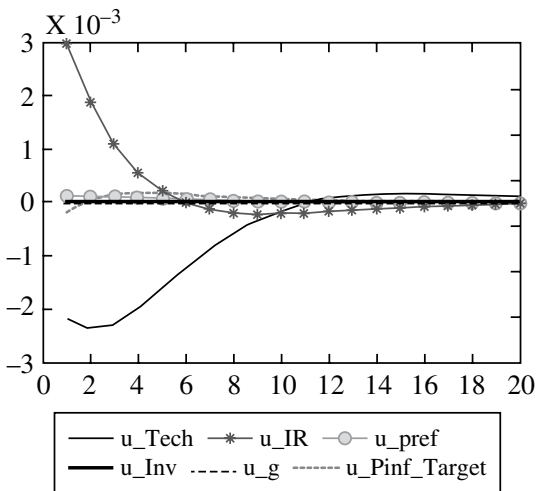

Real return (1 year bonds)

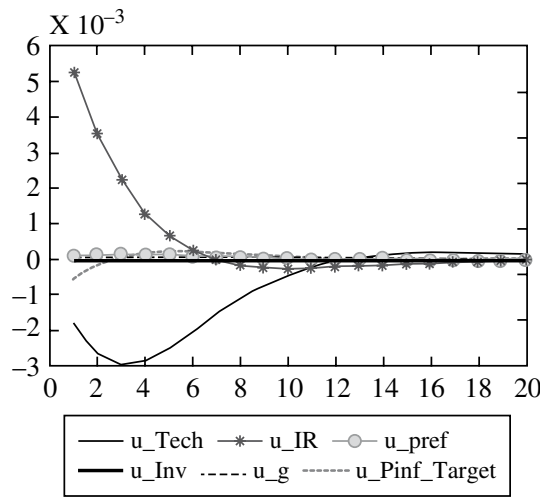

Real return (5 year bonds)

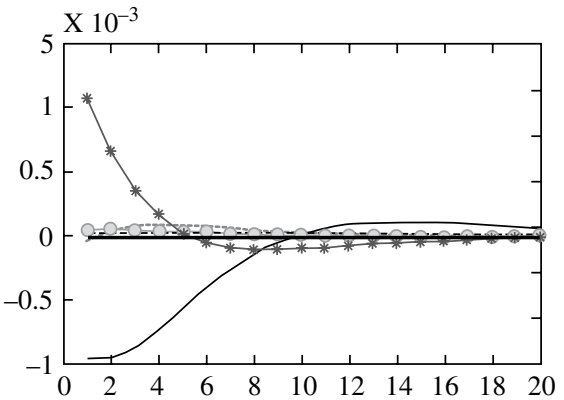

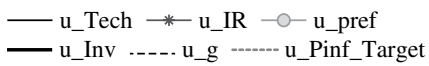




\section{FIGURE 3}

REAL AND NOMINAL YIELDS OF REAL BONDS, RESPONSES TO VARIOUS SHOCKS (1\%)

Real term spread (10 year bonds)

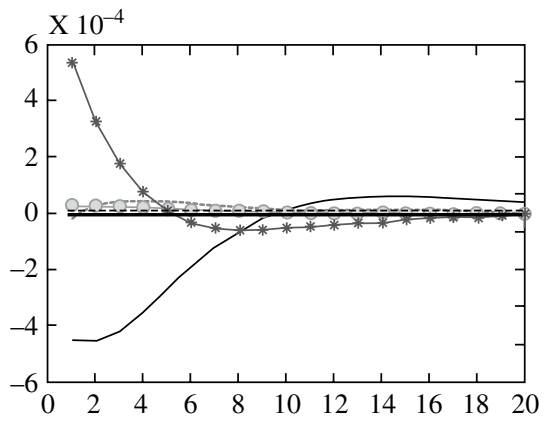

$$
\begin{aligned}
& - \text { u_Tech }- \text { - u_IR - o- u_pref } \\
& \text { u_Inv -.-.u_g - u_--- u_Pinf_Target }
\end{aligned}
$$

Nominal return (1 year bonds)

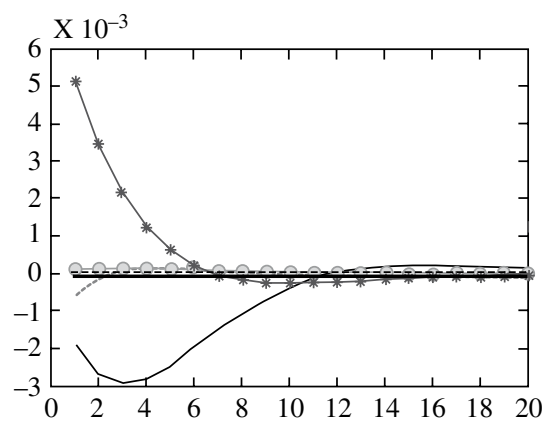

$$
\begin{aligned}
& - \text { u_Tech } \rightarrow \text { u_IR }- \text { - u u_pref } \\
& - \text { u_Inv ..-. u_g -.---- u_Pinf_Target }
\end{aligned}
$$

Nominal spot return

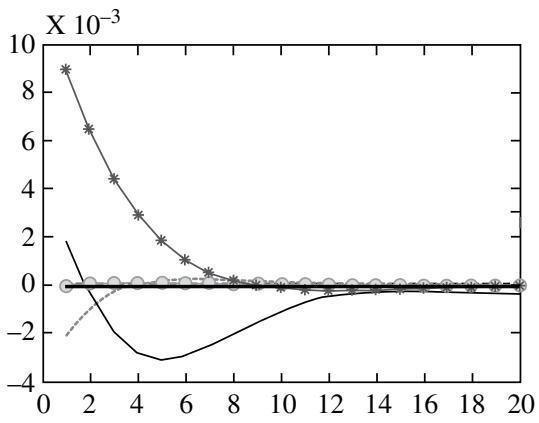

- u_Tech $\rightarrow$ - u_IR - $-u_{\text {_p pref }}$

- u_Inv .-.-. u_g ------ u_Pinf_Target

Nominal return (2 year bonds)

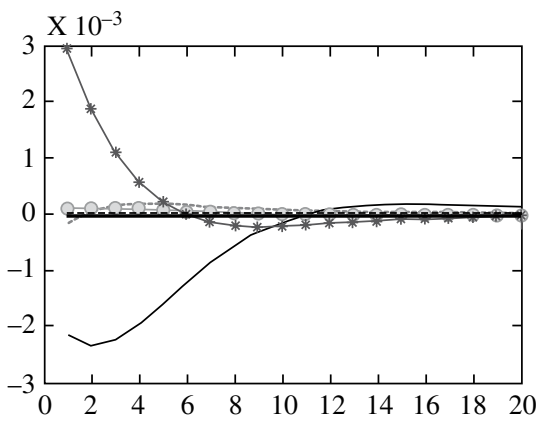

- u_Tech $\rightarrow$ - u_IR $-\mathrm{O}-\mathrm{u}$ _pref

- u_Inv .....u_g ------ u_Pinf_Target 


\section{FIGURE 4}

RESPONSES OF YIELDS OF LONG NOMINAL BONDS TO VARIOUS SHOCKS

Nominal return (5 year bonds)

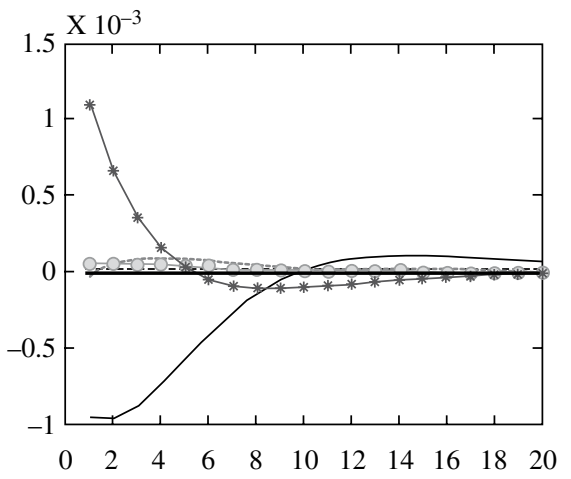

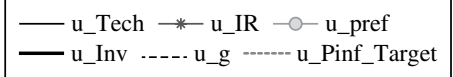

Nominal return (10 year bonds)

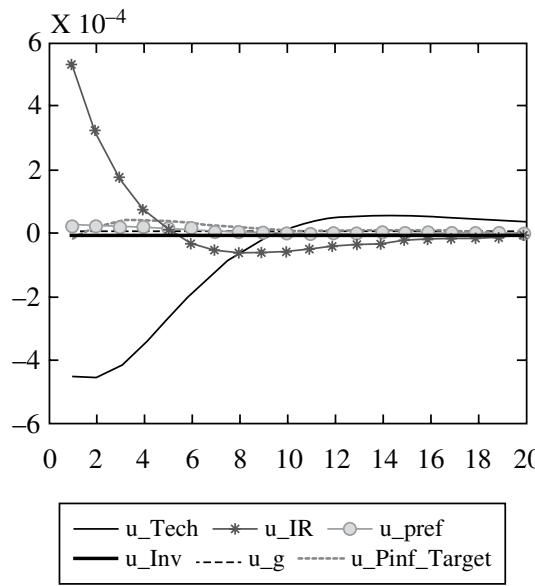

For the sake of comparison, we group in one figure the response of real and nominal bonds with all maturities to the same shock. Figure 5 presents the effect of a technology shock (upper left corner), MP shock (upper right corner), MP target (lower left corner) and government to GDP share shock (lower right corner). Overall, Figure 5 displays that, independently of the shock, the effect is more pronounced in bonds with shorter maturity (these bonds also show a larger gap between real and nominal denominations). In the case of a productivity shock the yield increases and then decreases to converge to the steady state from bellow (the effect is minor of long term bonds). A monetary policy tightening increases shorter bond rates (even more nominal bonds) than long term bonds. A positive shock to the MP target diminishes yields and an increase of government expenditure drives yields up.

Figure 6 reports on differences in yields' slopes or what is known in the literature as term risk or term premium for all maturities including break-even inflation under various shocks. The upper left corner displays a positive response of the inflation risk premium for technology shocks; slopes are negative on impact for all bonds, and then turn positive in the following quarters (the convergence is from above). A MP shock reduces slopes at all maturities (more for long bonds than short bonds) while increasing break-even inflation. A shock to MP inflation target increases slopes of bonds and reduces break-even inflation. A government expenditure shock increases slope on impact for shorter bonds, while it reduces slope of long bonds. 
We also calculated IRFs of variances of yields (not shown). We find that variances are time-varying and converge to zero after any shock ${ }^{35}$. The productivity shock seems to be the most important driver of variances.

\section{FIGURE 5}

EFFECTS ON NOMINAL AND REAL YIELDS OF MAIN SHOCKS (GROUPED BY SHOCKS)

Nominal and real bonds return (all maturities) IRFs to a Techn Shock

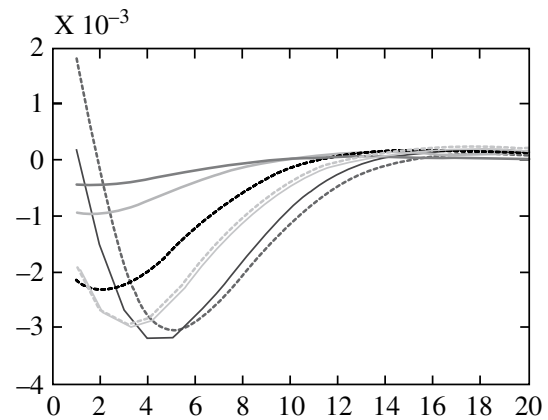

Nominal and real bonds return (all maturities) IRFs to the inflation target Shock

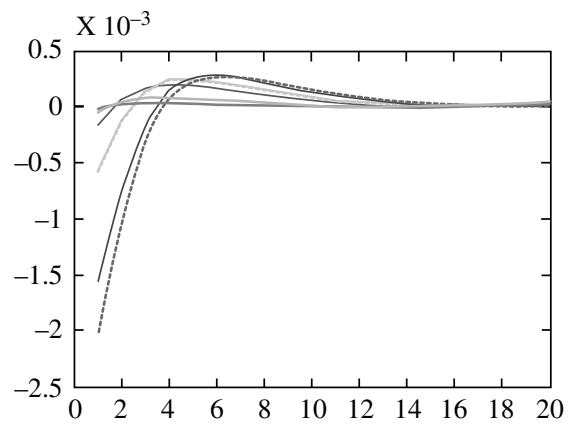

Nominal and real bonds return (all maturities) IRFs to IR Shock

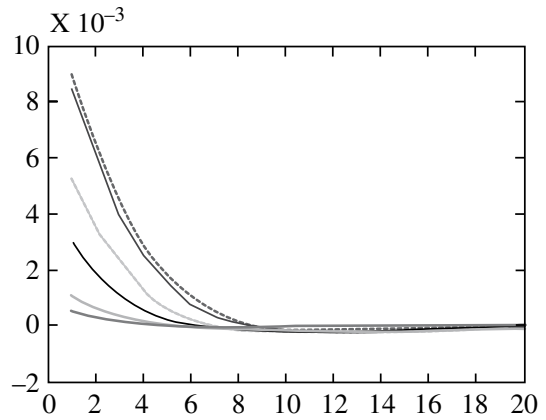

Nominal and real bonds return (all maturities) IRFs to the Gov't share Shock

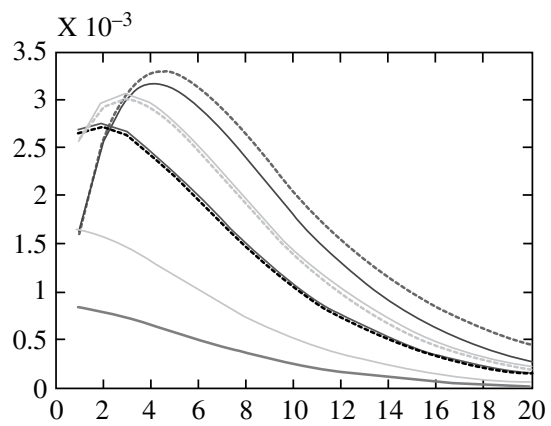

\begin{tabular}{|c|c|c|c|c|}
\hline - RR1 & RR4 & RR8 & - RR20 & - RR40 \\
\hline -...- RN1 & RN4 & -...-. RN8 & 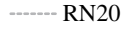 & $\ldots-$ RN40 \\
\hline
\end{tabular}

35 The radius within which the approximation is valid becomes smaller, the higher order of approximation. Thus, if the shock is large enough, moments may not converge. 


\section{FIGURE 6}

\section{SLOPE OF BREAKEVEN INFLATION AND TERM PREMIUMS RESPONSES TO MAIN SHOCKS (GROUPED BY SHOCKS)}

Nominal real term spreads and Breakeven inflation (all maturities) IRFs to a Techn Shock

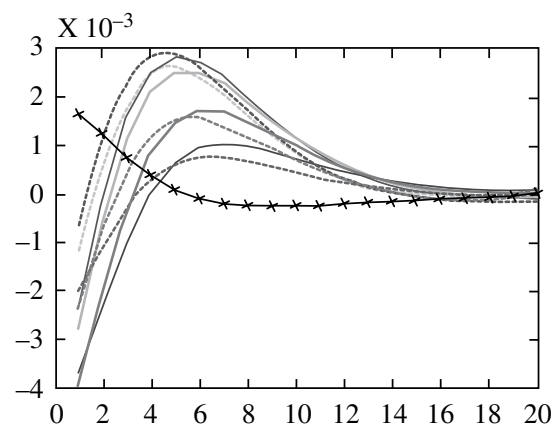

Nominal real term spreads and Breakeven inflation (all maturities) IRFs to a inflation target Shock

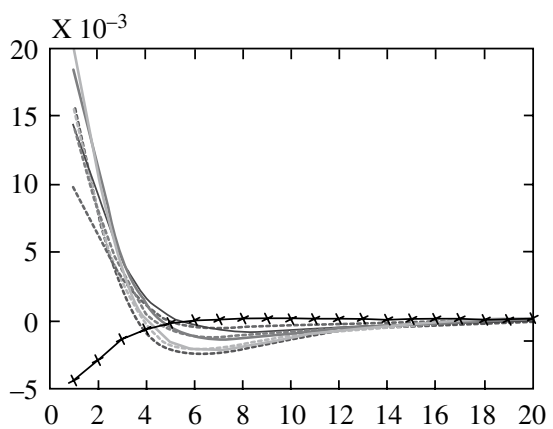

Nominal real term spreads and Breakeven inflation (all maturities) IRFs to a IR Shock

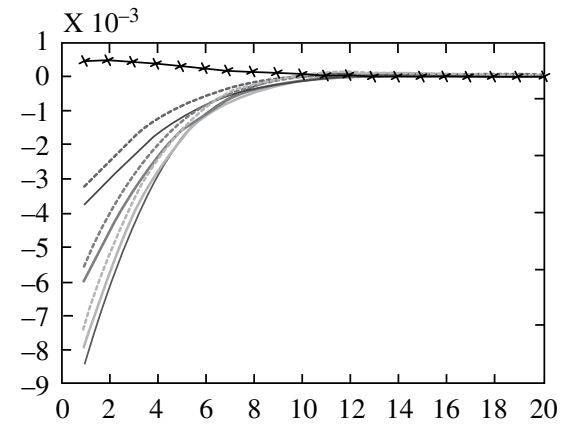

Nominal real term spreads and Breakeven inflation (all maturities) IRFs to the Gov't share Shock

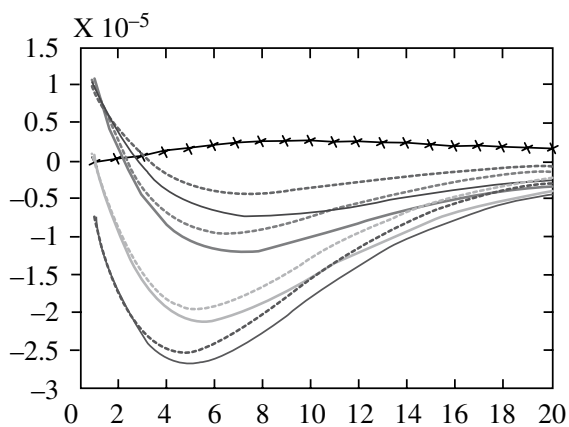

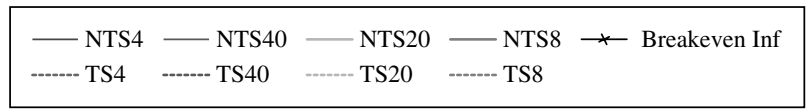




\section{CONCLUSIONS}

We reviewed extensively the literature on asset pricing models that try to replicate moments of financial and macro variables jointly. Especial emphasis has been placed on the evidence for Chile. We found that we lack for a structural model to help interpreting concepts such as break-even inflation, term premium, etc.

To shorten this gap we build the simplest DSGE model to study main financial issues just mentioned and how these objects may have feedback on the real economy.

We observe that the higher the model's approximation, the larger the curvature of the yields.

The results suggest that productivity and MP shocks (either additive or to the target) induce the largest returns responses, which are more important for short bonds. By far the MP shock is the most disturbing for returns, term spreads (yields' slope) and break-even inflation measures.

As the model is approximated up to third order, variances are time-varying and converge to zero for any shock. The productivity shock seems to be the most important driver of variances.

The break-even inflation associated to all shocks is shown to be very small.

\section{REFERENCES}

ALFARO, R. (2009). "La curva de rendimiento bajo Nelson-Siegel”, Working Papers Central Bank of Chile 531. Central Bank of Chile.

ALVAREZ, F. and U. JERMANN (1999). "Quantitative asset pricing implications of endogenous solvency constraints", Working Papers 99-5. Federal Reserve Bank of Philadelphia.

AMISANO, G. and O. TRISTANI (2009). A DSGE model of the term structure with regime shifts. Mimeo.

ANDRES, J., J. LOPEZ-SALIDO and E. NELSON (2004). "Tobin's Imperfect Asset Substitution in Optimizing General Equilibrium", Journal of Money, Credit and Banking 36(4), pp. 665-690.

ANG, A. and J. CHEN (2002). "Asymmetric correlations of equity portfolios", Journal of Financial Economics 63(3), pp. 443-494.

ANG, A. and M. PIAZZESI (2003). "A no-arbitrage vector autoregression of term structure dynamics with macroeconomic and latent variables", Journal of Monetary Economics 50(4), pp. 745-787.

ANG, A., G. BEKAERT and M. WEI (2008). "The Term Structure of Real Rates and Expected Inflation", Journal of Finance 63(2), pp. 797-849.

ANG, A., J. BOIVIN, S. DONG and R. LOO-KUNG (2009). "Monetary Policy Shifts and the Term Structure", NBER Working Papers 15270. National Bureau of Economic Research, Inc.

BALFOUSSIA, H. and M. WICKENS (2007). "Macroeconomic Sources of Risk in the Term Structure", Journal of Money, Credit and Banking 39(1), pp. 205-236.

BANSAL, R. and A. YARON (2004). "Risks for the Long Run: A Potential Resolution of Asset Pricing Puzzles", Journal of Finance 59(4), pp. 1481-1509.

BEKAERT, G., S. CHO and A. MORENO (2005). "New-Keynesian Macroeconomics and the Term Structure", NBER Working Papers 11340. National Bureau of Economic Research, Inc.

BERNIER, M. and F. ALARCON (2009). "Diferencias en Medidas de Compensacion Inflacionaria y SWAP Spread”, Notas de Investigación Journal Economía Chilena 12(1), pp. 105-116.

BILS, M. and P.J. KLENOW (2004). "Some Evidence on the Importance of Sticky Prices", Journal of Political Economy 112(5), pp. 947-985.

BLANCHARD, O. and J. GALI (2007). "Real Wage Rigidities and the New Keynesian Model", Journal of Money, Credit and Banking 39(s1), pp. 35-65.

BOLDRIN, M., L. CHRISTIANO and J. FISHER (2001). "Habit Persistence, Asset Returns, and the Business Cycle", American Economic Review 91(1), pp. 149-166. 
BURASCHI, A. and A. JILTSOV (2005). "Inflation risk premia and the expectations hypothesis", Journal of Financial Economics 75(2), pp. 429-490.

CALVO, G. (1983). "Staggered Prices in a Utility-Maximizing Framework", Journal of Monetary Economics 12(3), 983a.A CS998.

CAMPBELL, J. (1999). "Asset prices, consumption, and the business cycle”, Chap. 19, pp. 1231-1303 of: Taylor, J. B. and Woodford, M. (eds.), Handbook of Macroeconomics. Handbook of Macroeconomics, vol. 1. Elsevier.

CAMPBELL, J. and J. COCHRANE (1999). "By force of habit: a consumption-based explanation of aggregate stock market behavior", Journal of Political Economy 107(2), pp. 205-251.

CAMPBELL, J. and J. COCHRANE (2000). "Explaining the Poor Performance of Consumption-based Asset Pricing Models", Journal of Finance 55(6), pp. 2863-2878.

CAMPBELL, J., A. LO and A. MACKINLAY (1997). The Econometrics of Financial Markets. New Yersey: Princeton University Press.

CANZONERI, M., R. CUMBY and B. DIBA (2007). "The Cost of Nominal Rigidity in NNS Models", Journal of Money, Credit and Banking 39(7), pp. 1563-1586.

CEBALLOS, L. and C. SAAVEDRA (2009). "Compensación inflacionaria: medidas de expectativas y premios", Minuta GAM 17/2009. Banco de Chile.

CHARI, V.V., P.J. KEHOE and E.R. McGRATTAN (2009). "New Keynesian Models: Not Yet Useful for Policy Analysis", American Economic Journal: Macroeconomics 1(1), pp. 242-66.

CHIB, S., K. KANG and S. RAMAMURTHY (2010). "Term Structure of Interest Rates in a DSGE Model with Regime Changes", Mimeo.

CHUMACERO, R. and L. OPAZO (2008). "Compensación Inflacionaria en Chile”, Working Papers Central Bank of Chile 468. Central Bank of Chile.

COCHRANE, J. (2005). Asset Pricing: (Revised). New Yersey: Princeton University Press.

COCHRANE, J. (2007). Commentary on "Macroeconomic implications of changes in the term premium", Review, pp. 271-282.

D' ACUÑA, S., S. GODOY and N. MALANDRE (2009). "Descripción del funcionamiento del mercado secundario de bonos soberanos locales en Chile", Economic Statistics Series 72. Central Bank of Chile.

DANTHINE, J. and J. DONALDSON (2002). "Labour Relations and Asset Returns", Review of Economic Studies 69(1), pp. 41-64.

DANTHINE, J., J. DONALDSON and P. SICONOLFI (2005). "Distribution Risk and Equity Returns", CEPR Discussion Papers 5425. C.E.P.R. Discussion Papers.

DE GRAEVE, F., M. DOSSCHE, M. EMIRIS, H. SNEESSENS and R. WOUTERS (2008). "Risk premiums and macroeconomic dynamics in a heterogeneous agent model", Research series 20081025. National Bank of Belgium.

DE GRAEVE, F., M. EMIRIS and R. WOUTERS (2009). "A structural decomposition of the US yield curve", Journal of Monetary Economics 56(4), pp. 545-559.

DE PAOLI, B. and P. ZABCZYK (2009). "Why do risk premia vary over time? A theoretical investigation under habit formation", Bank of England working papers 361. Bank of England.

DE PAOLI, B., A. SCOTT and O. WEEKEN (2007). "Asset pricing implications of a New Keynesian model", Bank of England working papers 326. Bank of England.

DIEBOLD, F. and C. LI (2006). "Forecasting the term structure of government bond yields", Journal of Econometrics 130(2), pp. 337-364.

DOH, T. (2009). "Yield curve in an estimated nonlinear macro model", Research Working Paper RWP 09-04. Federal Reserve Bank of Kansas City.

EMIRIS, M. (2006). "The term structure of interest rates in a DSGE model", Research series 200607-2. National Bank of Belgium.

EPSTEIN, L. and S. ZIN (1989). "Substitution, Risk Aversion, and the Temporal Behavior of Consumption and Asset Returns: A Theoretical Framework", Econometrica 57(4), pp. 937-69.

EPSTEIN, L. and S. ZIN (1991). "Substitution, Risk Aversion, and the Temporal Behavior of Consumption and Asset Returns: An Empirical Analysis”, Journal of Political Economy 99(2), pp. 263.86.

FERNANDEZ-VILLAVERDE, J., P. GUERRON-QUINTANA, J. RUBIO-RAMIREZ, and M. URIBE (2009). "Risk Matters: The Real Effects of Volatility Shocks", NBER Working Papers 14875. National Bureau of Economic Research, Inc. 
FUENTES, R., A. JARA, K. SCHMIDT-HEBBEL, M. TAPIA and E. ARRANO (2003). "Efectos de la Nominalización de la Política Monetaria en Chile", Working Papers Central Bank of Chile 197. Central Bank of Chile.

GALLMEYER, M., B. HOLLIFIELD and S. ZIN (2005). "Taylor rules, McCallum rules and the term structure of interest rates", Journal of Monetary Economics 52(5), pp. 921-950.

GUVENEN, F. (2005). "A Parsimonious Macroeconomic Model for Asset Pricing: Habit Formation of Cross-sectional Heterogeneity?", Finance 0507009. EconWPA.

GUVENEN, F. (2007). "Do Stockholders Share Risk More Effectively than Nonstockholders?", The Review of Economics and Statistics 89(2), pp. 275-288.

GUVENEN, F. (2009). "A Parsimonious Macroeconomic Model for Asset Pricing”, NBER Working Papers 15243. National Bureau of Economic Research, Inc.

HÖRDAHL, P. and O. TRISTANI (2007). "Inflation risk premia in the term structure of interest rates", BIS Working Papers 228. Bank for International Settlements.

HÖRDAHL, P., O. TRISTANI and D. VESTIN (2008). "The Yield Curve and Macroeconomic Dynamics", Economic Journal 118(533), pp. 1937-1970.

JERMANN, U. (1998). "Asset pricing in production economies", Journal of Monetary Economics 41(2), pp. 257-275.

JERMANN, U. and V. QUADRINI (2009). "Macroeconomic Effects of Financial Shocks", NBER Working Papers 15338. National Bureau of Economic Research, Inc.

JERVIS, P. (2007). "La Compensación Inflacionaria y sus Componentes en Chile", Notas de Investigacion Journal Economía Chilena 10(2), pp. 27-56.

JUDD, K. (1998). Numerical Methods in Economics. Cambridge, Massachusetts: The MIT Press.

KOOP, G., M. PESARAN and S. POTTER (1996). "Impulse response analysis in nonlinear multivariate models", Journal of Econometrics 74(1), pp. 119-147.

LARRAIN, M. (2007). "Inflation Compensation and Inflation Expectations in Chile", Working Papers Central Bank of Chile 421. Central Bank of Chile.

LETTAU, M. and H. UHLIG (2000). "Can Habit Formation be Reconciled with Business Cycle Facts?", Review of Economic Dynamics 3(1), pp. 79-99.

LUCAS, Jr., R.E. (1978). “Asset prices in an exchange economy", Econometrica 46(6), pp. 1429-1445.

MARZO, M., U. SODERSTROM and P. ZAGAGLIA (2009). "The Term Structure of Interest Rates and the Monetary Transmission Mechanism", Tech. rept. Mimeo.

MEHRA, R. and E. PRESCOTT (1985). "The equity premium: A puzzle", Journal of Monetary Economics 15(2), pp. 145-161.

MOLLER ANDREASEN, M. (2008). "Explaining Macroeconomic and Term Structure Dynamics Jointly in a Non-linear DSGE Model", CREATES Research Papers 2008-43. School of Economics and Management, University of Aarhus.

MORALES, M. (2007). "The Yield Curve and Macroeconomic Factors in the Chilean Economy”, Working Papers. Seminarios de Macroeconomía y Finanzas, Banco Central de Chile.

NELSON, C. and A. SIEGEL (1987). "Parsimonious Modeling of Yield Curves", Journal of Business 60(4), pp. 473-489.

OCHOA, M. (2006). "Interpreting an Affine Term Structure Model for Chile", Working Papers Central Bank of Chile 380. Central Bank of Chile.

POTTER, S. (2000). "Nonlinear impulse response functions", Journal of Economic Dynamics and Control 24(10), pp. 1425-1446.

RAVENNA, R. and J. SEPPALA (2006). "Monetary policy and rejections of the expectations hypothesis", Research Discussion Papers 25/2006. Bank of Finland.

RAVENNA, R. and J. SEPPALA (2007). "Monetary policy, expected inflation and inflation risk premia", Research Discussion Papers 18/2007. Bank of Finland.

RUDEBUSCH, G. and E. SWANSON (2008). "Examining the bond premium puzzle with a DSGE model", Journal of Monetary Economics 55 (Supplement), S111-S126.

RUDEBUSCH, G. and E. SWANSON (2009). "The bond premium in a DSGE model with long-run real and nominal risks", Working Paper Series 2008-31. Federal Reserve Bank of San Francisco.

RUDEBUSCH, G., B. SACK and E. SWANSON (2007). "Macroeconomic implications of changes in the term premium", Federal Reserve Bank of St. Louis Review, pp. 241-270. 
SMETS, F. and R. WOUTERS (2005). "Comparing shocks and frictions in US and euro area business cycles: a Bayesian DSGE Approach", Journal of Applied Econometrics 20(2), pp. 161-183.

SMETS, F. and R. WOUTERS (2007). "Shocks and Frictions in US Business Cycles: A Bayesian DSGE Approach", American Economic Review 97(3), pp. 586-606.

SWANSON, E. (2007). "What we do and don't know about the term premium", FRBSF Economic Letter.

TAYLOR, J.B. (1993). "Discretion versus Policy Rules in Practice", Carnegie-Rochester Conference Series on Public Policy 39, pp. 195-214.

UHLIG, H. (2007). "Explaining Asset Prices with External Habits and Wage Rigidities in a DSGE Model", American Economic Review 97(2), pp. 239-243.

VAN BINSBERGEN, J., J. FERNANDEZ-VILLAVERDE, R. KOIJEN and J. RUBIO-RAMIREZ (2010). "The Term Structure of Interest Rates in a DSGE Model with Recursive Preferences", NBER Working Papers 15890. National Bureau of Economic Research, Inc.

VERDELHAN, A. (2010). "A Habit-Based Explanation of the Exchange Rate Risk Premium", Journal of Finance 65(1), pp. 123-146.

WACHTER, J. (2006). "A consumption-based model of the term structure of interest rates", Journal of Financial Economics 79(2), pp. 365-399.

WICKENS, M. (2008). Macroeconomic Theory: A Dynamic General Equilibrium Approach, New Yersey: Princeton University Press.

WOODFORD, M. (2003). Interest and Prices: Foundations of a Theory of Monetary Policy, Princeton University Press.

ZAGAGLIA, P. (2009a). "Forecasting with a DSGE Model of the term Structure of Interest Rates: The Role of the Feedback", Research Papers in Economics 2009:14. Stockholm University, Department of Economics.

ZAGAGLIA, P. (2009b). "What Drives the Term Structure in the Euro Area? Evidence from a Model with Feedback", Research Papers in Economics 2009:12. Stockholm University, Department of Economics. 


\section{APPENDIX}

\section{A. Multinearity property of cumulants}

The multinearity property of cumulants can be written as:

$$
\mathcal{K}\left(X+Y, Z_{1}, Z_{2}, Z_{3} \ldots\right)=\mathcal{K}\left(X, Z_{1}, Z_{2}, Z_{3} \ldots\right)+\mathcal{K}\left(Y, Z_{1}, Z_{2}, Z_{3} \ldots\right) .
$$

To gain insight, it can be shown that $\mathcal{K}_{2}(X+Y)=V(X+Y)$, where $V()$ is the variance operator and $\mathcal{K}_{2}$ is the second cumulant. By developing these expressions the equality becomes clear:

$$
\begin{gathered}
\mathcal{K}_{2}(X+Y)=\left(\begin{array}{l}
2 \\
0
\end{array}\right) \mathcal{K}(Y, Y)+\left(\begin{array}{l}
2 \\
1
\end{array}\right) \mathcal{K}(X, Y)+\left(\begin{array}{l}
2 \\
2
\end{array}\right) \mathcal{K}(X, X), \\
V(X+Y)=V(X)+2 \operatorname{CoV}(X, Y)+V(Y) .
\end{gathered}
$$

Now, develop the third cumulant:

$$
\begin{gathered}
\mathcal{K}_{3}(X+Y)=\left(\begin{array}{l}
3 \\
0
\end{array}\right) \mathcal{K}(Y, Y, Y)+\left(\begin{array}{l}
3 \\
1
\end{array}\right) \mathcal{K}(X, Y, Y)+\left(\begin{array}{l}
3 \\
2
\end{array}\right) \mathcal{K}(X, X, Y)+\left(\begin{array}{l}
3 \\
3
\end{array}\right) \mathcal{K}(X, X, X), \\
\mathcal{K}_{3}(X+Y)=\mathcal{K}(Y, Y, Y)+3 \mathcal{K}(X, Y, Y)+3 \mathcal{K}(X, X, Y)+\mathcal{K}(X, X, X) .
\end{gathered}
$$

Besides, it can be shown that:

$$
\begin{aligned}
\mathcal{K}(X, Y, Y)= & E(X, Y, Y)-E(X, Y) E(Y)-E(X, Y) E(Y)-E(Y, Y) E(X) \\
& -2 E(Y) E(Y) E(X)
\end{aligned}
$$

and the application of the certainty equivalence principle implies that $\mathcal{K}(X, Y, Y)=$ $E(X, Y, Y)$ so we get:

$$
\begin{aligned}
\mathcal{K}_{3}(X+Y) & =\mathcal{K}(Y, Y, Y)+3 E(X, Y, Y)+3 E(X, X, Y)+\mathcal{K}(X, X, X) \\
& =S k(Y)+S k(X)+3 E(X, Y, Y)+3 E(X, X, Y),
\end{aligned}
$$

where $E(X, Y, Y)=\frac{1}{T} \sum_{t=1}^{T}\left(X_{t}-E(X)\right)\left(Y_{t}-E(Y)\right)^{2}$ iff $X_{t}$ and $Y_{t}$ are uniformly distributed with finite population of size $T$.

This is an useful property that can be extended to order $n$, so we get $\mathcal{K}_{n}(X+Y)$, known also as Faa di Bruno formula. We apply it to derive the last term of Eq. (31): 


$$
\begin{aligned}
S k_{t}\left[s d f_{t+1}+r_{t+1}^{e q}\right]= & \mathcal{K}\left(s d f_{t+1}, s d f_{t+1}, s d f_{t+1}\right)+3 \underbrace{\mathcal{K}\left(r_{t+1}^{e q}, s d f_{t+1}, s d f_{t+1}\right)}_{\equiv \mathcal{A}} \\
& +3 \underbrace{\mathcal{K}\left(r_{t+1}^{e q}, r_{t+1}^{e q}, s d f_{t+1}\right)}_{\equiv \mathcal{B}}+\mathcal{K}\left(r_{t+1}^{e q}, r_{t+1}^{e q}, r_{t+1}^{e q}\right),
\end{aligned}
$$

where $\mathcal{A}$ is solved in details:

$$
\begin{aligned}
\mathcal{A} \equiv & K\left(r_{t+1}^{e q}, s d f_{t+1}, s d f_{t+1}\right) \\
= & \mathrm{E}_{t}\left(r_{t+1}^{e q}, s d f_{t+1}, s d f_{t+1}\right)-\mathrm{E}_{t}\left(r_{t+1}^{e q}, s d f_{t+1}\right) \mathrm{E}_{t}\left(s d f_{t+1}\right)-\mathrm{E}_{t}\left(r_{t+1}^{e q}, s d f_{t+1}\right) \mathrm{E}_{t}\left(s d f_{t+1}\right) \\
& -\mathrm{E}_{t}\left(s d f_{t+1}+s d f_{t+1}\right) \mathrm{E}_{t}\left(r_{t+1}^{e q}\right)-2 \mathrm{E}_{t}\left(s d f_{t+1}\right) \mathrm{E}_{t}\left(s d f_{t+1}\right) \mathrm{E}_{t}\left(r_{t+1}^{e q}\right), \\
= & \mathrm{E}_{t}\left(r_{t+1}^{e q}, s d f_{t+1}, s d f_{t+1}\right)-2 \mathrm{E}_{t}\left(r_{t+1}^{e q}+s d f_{t+1}\right) \mathrm{E}_{t}\left(s d f_{t+1}\right) \\
& -\mathrm{E}_{t}\left(s d f_{t+1}+s d f_{t+1}\right) \mathrm{E}_{t}\left(r_{t+1}^{e q}\right)-2 \mathrm{E}_{t}\left(s d f_{t+1}\right) \mathrm{E}_{t}\left(s d f_{t+1}\right) \mathrm{E}_{t}\left(r_{t+1}^{e q}\right), \\
= & \mathrm{E}_{t}\left(r_{t+1}^{e q}, s d f_{t+1}, s d f_{t+1}\right)-2 C o v_{t}\left(r_{t+1}^{e q}+s d f_{t+1}\right) \mathrm{E}_{t}\left(s d f_{t+1}\right) \\
& -\mathrm{V}_{t}\left(s d f_{t+1}\right) \mathrm{E}_{t}\left(r_{t+1}^{e q}\right)-2\left[\mathrm{E}_{t}\left(s d f_{t+1}\right)\right]^{2} \mathrm{E}_{t}\left(r_{t+1}^{e q}\right), \\
= & \mathrm{E}_{t}\left(r_{t+1}^{e q}\right) V_{t}\left(s d f_{t+1}\right)-2 \mathrm{E}_{t}\left(r_{t+1}^{e q}\right) V_{t}\left(s d f_{t+1}\right) \\
& -\mathrm{V}_{t}\left(s d f_{t+1}\right) \mathrm{E}_{t}\left(r_{t+1}^{e q}\right)-2\left[\mathrm{E}_{t}\left(s d f_{t+1}\right)\right]^{2} \mathrm{E}_{t}\left(r_{t+1}^{e q}\right), \\
= & -2 \mathrm{E}_{t}\left(r_{t+1}^{e q}\right)\left[V_{t}\left(s d f_{t+1}\right)+\left[\mathrm{E}_{t}\left(s d f_{t+1}\right)\right]^{2}\right],
\end{aligned}
$$

proceeding similarly for $B$, we get $\mathcal{K}\left(r_{t+1}^{e q}, r_{t+1}^{e q}, s d f_{t+1}\right)=-2\left[V_{t}\left(r_{t+1}^{e q}\right)+\left[E_{t}\left(r_{t+1}^{e q}\right)\right]^{2}\right] E_{t}\left(s d f_{t+1}\right)$. If we concentrate on $\mathcal{A}$ and $B$, the square of the expectation terms can be rewritten as: $E_{t}\left[\left(s d f_{t+1}\right)^{2}\right]=V_{t}\left(s d f_{t+1}\right)+\left[E_{t}\left(s d f_{t+1}\right)\right]^{2}$ and $E_{t}\left[\left(r_{t+1}^{e q}\right)^{2}\right]=V_{t}\left(r_{t+1}^{e q}\right)+\left[E_{t}\left(r_{t+1}^{e q}\right)\right]^{2}$. Then, plugging them into Eq. (34), we get:

$$
\begin{aligned}
S k_{t}\left[s d f_{t+1}+r_{t+1}^{e q}\right]= & S k_{t}\left[s d f_{t+1}\right]+S k_{t}\left[r_{t+1}^{e q}\right] \\
& -6 E_{t}\left(r_{t+1}^{e q}\right) E_{t}\left[\left(s d f_{t+1}\right)^{2}\right] \\
& -6 E_{t}\left(s d f_{t+1}\right) E_{t}\left[\left(r_{t+1}^{e q}\right)^{2}\right] .
\end{aligned}
$$


We develop Eq. (32) following the same steps as before:

$$
\begin{aligned}
& S k_{t}\left[\pi_{t+h}-s d f_{t+h}\right]=S k_{t}\left[\pi_{t+h}\right]-S k_{t}\left[s d f_{t+h}\right] \\
& -3 V_{t}\left(\pi_{t+h}\right) E_{t}\left(s d f_{t+h}\right)+6 E_{t}\left[s d f_{t+h}\right] V_{t}\left[\pi_{t+h}\right] \\
& +3 V_{t}\left(\pi_{t+h}\right) E_{t}\left(s d f_{t+h}\right)+6\left[E_{t}\left(\pi_{t+h}\right)\right]^{2} E_{t}\left(s d f_{t+h}\right) \\
& +3 V_{t}\left[s d f_{t+h}\right] E_{t}\left[\pi_{t+h}\right]-6 V_{t}\left[s d f_{t+h}\right] E_{t}\left(\pi_{t+h}\right) \\
& +3 V_{t}\left[s d f_{t+h}\right] E_{t}\left[\pi_{t+h}\right]+6\left[E_{t}\left(s d f_{t+h}\right)\right]^{2} E_{t}\left(\pi_{t+h}\right) \text {, } \\
& S k_{t}\left[\pi_{t+h}-s d f_{t+h}\right]=S k_{t}\left[\pi_{t+h}\right]-S k_{t}\left[s d f_{t+h}\right] \\
& +6 E_{t}\left[s d f_{t+h}\right]\left\{V_{t}\left[\pi_{t+h}\right]+\left[E_{t}\left(\pi_{t+h}\right)\right]^{2}\right\} \\
& +6\left[E_{t}\left(s d f_{t+h}\right)\right]^{2} E_{t}\left(\pi_{t+h}\right), \\
& S k_{t}\left[\pi_{t+h}-s d f_{t+h}\right]=S k_{t}\left[\pi_{t+h}\right]-S k_{t}\left[s d f_{t+h}\right] \\
& +6 E_{t}\left[s d f_{t+h}\right] E_{t}\left[\left(\pi_{t+h}\right)^{2}\right] \\
& +6\left[E_{t}\left(s d f_{t+h}\right)\right]^{2} E_{t}\left[\pi_{t+h}\right] \text {. }
\end{aligned}
$$

Analogously, break-even inflation (33) results from the difference of:

$$
\begin{aligned}
& -E_{t}\left[s d f_{t+1}\right]+E_{t}\left[\pi_{t+1}\right] \\
& E_{t}\left[r_{1, t+1}^{b n}\right] \simeq \quad-\frac{1}{2} V_{t}\left[s d f_{t+1}\right]+\frac{1}{2} V_{t}\left[\pi_{t+1}\right]-\operatorname{CoV}_{t}\left[s d f_{t+1}, \pi_{t+1}\right] \\
& +\left\{\frac{1}{6} S k_{t}\left[\pi_{t+1}\right]-\frac{1}{6} S k_{t}\left[s d f_{t+1}\right]+E_{t}\left[s d f_{t+1}\right] E_{t}\left[\left(\pi_{t+h}\right)^{2}\right]+\left[E_{t}\left(s d f_{t+1}\right)\right]^{2} E_{t}\left[\pi_{t+1}\right]\right\},
\end{aligned}
$$

with

$$
E_{t}\left[r_{1, t+1}^{b r}\right] \simeq-\left(E_{t}\left[s d f_{t+1}\right]+\frac{1}{2} V_{t}\left[s d f_{t+1}\right]+\frac{1}{6} S k_{t}\left[s d f_{t+1}\right]\right)
$$

\section{B. Steady State (SS)}

The SS inflation is zero, $\Pi=1$, and the interest rate is $i=\beta^{-1}$. Taking into account the fact all consumers are identical and that $\tilde{\Lambda} P=\Lambda$ and $\tilde{\Lambda}=\Gamma\left[1-\Psi\left(\frac{I}{K}-\delta\right)\right]$, the FOC w.r.t. capital evaluated at the SS can be rewritten as: 


$$
\left(1-\beta\left[(1-\delta)-\frac{1}{2} \Psi\left(\frac{I}{K}-\delta\right)^{2}+\Psi\left(\frac{I}{K}-\delta\right) \frac{I}{K}\right]\right) \Gamma=\beta \frac{\Gamma\left[1-\Psi\left(\frac{I}{K}-\delta\right)\right]}{P} R^{k} \text {, recall }
$$
that at the SS all the undesired investment is zero, so the return on capital is:

$$
r^{k}=\frac{1-\beta(1-\delta)}{\beta}
$$

Because of optimality, at the SS we know that $P=\mu_{p} M C$, or in real terms:

$$
m c=\frac{1}{\mu_{P}} .
$$

SS investment arises from the law of motion of capital:

$$
I=\delta K
$$

and from the firm's optimality condition (21) at the SS:

$$
\frac{K}{L}=\left(\frac{\alpha}{1-\alpha}\right) \frac{w}{r^{k}}
$$

To pin down $w_{t}$, equalize the SS real marginal cost, $m c=\frac{1}{A} \frac{\left(r^{k}\right)^{\alpha} w^{1-\alpha}}{\alpha^{\alpha}(1-\alpha)^{1-\alpha}}$, to Eq. (37) and replace by (36):

$$
\begin{gathered}
\frac{1}{\mu_{P}}=\frac{1}{A} \frac{\left(\frac{1-\beta(1-\delta)}{\beta}\right)^{\alpha} w^{1-\alpha}}{\alpha^{\alpha}(1-\alpha)^{1-\alpha}} \\
w=\left(\frac{A}{\mu_{P}}\right)^{\frac{1}{1-\alpha}} \alpha^{\frac{\alpha}{1-\alpha}}(1-\alpha)\left(\frac{1-\beta(1-\delta)}{\beta}\right)^{\frac{\alpha}{\alpha-1}} .
\end{gathered}
$$

Dividing (40) by (36), it follows that the relative inputs' price is:

$$
\begin{gathered}
\frac{w}{r^{k}}=\frac{\left(\frac{A}{\mu_{P}}\right)^{\frac{1}{1-\alpha}} \alpha^{\frac{\alpha}{1-\alpha}}(1-\alpha)\left(\frac{1-\beta(1-\delta)}{\beta}\right)^{\frac{\alpha}{\alpha-1}}}{\frac{1-\beta(1-\delta)}{\beta}}, \\
=\left(\frac{A}{\mu_{P}}\right)^{\frac{1}{1-\alpha}} \alpha^{\frac{\alpha}{1-\alpha}}(1-\alpha)\left(\frac{1-\beta(1-\delta)}{\beta}\right)^{\frac{1}{\alpha-1}} .
\end{gathered}
$$


Real profits are given by:

$$
\begin{gathered}
\mathfrak{B}=\frac{Y}{m c}-\underset{=Y \text { (under perfect competition) }}{(\underbrace{w L+r^{k} k})}-F C . \\
\mathfrak{B}=\mu_{P} Y-Y-F C=0 \Rightarrow F C=\left(\mu_{P}-1\right) Y, \\
F C=\left(\mu_{P}-1\right) A K^{\alpha} L^{1-\alpha}-\left(\mu_{P}-1\right) F C, \\
F C=\frac{\left(\mu_{P}-1\right)}{\mu_{P}} A K^{\alpha} L^{1-\alpha} .
\end{gathered}
$$

The marginal utility of consumption from equation (3) in the SS is

$$
\tilde{\Lambda}=\frac{(1-\beta b)}{C(1-b)} \text {. }
$$

As the real wage is divided by the markup in the SS, the wage equation simplifies in the SS to:

$$
-\chi_{L} L^{\chi}+\frac{\tilde{\Lambda}}{\mu_{W}} w=0
$$

which implies that $L=\left(\frac{\tilde{\Lambda}}{\chi_{L} \mu_{w}} w\right)^{1 / \chi}$, where $w$ comes from Eq. (40). Thus,

$$
L=\left(\frac{\tilde{\Lambda}}{\chi_{L} \mu_{W}}\left(\frac{A}{\mu_{P}}\right)^{\frac{1}{1-\alpha}} \alpha^{\frac{\alpha}{1-\alpha}}(1-\alpha)\left(\frac{1-\beta(1-\delta)}{\beta}\right)^{\frac{\alpha}{\alpha-1}}\right)^{1 / \chi}
$$

The resource constraint at the home final goods level can be written as (recall that $\Delta=1, \Phi(1)=0)$ :

$$
A K^{\alpha} L^{1-\alpha}-F C=C+I+G
$$

Substituting $F C$ from (43) into (46) and $G$ by $\left(1-\frac{1}{g}\right)\left(A K^{\alpha} L^{1-\alpha}-\frac{\left(\mu_{P}-1\right)}{\mu_{P}} A K^{\alpha} L^{1-\alpha}\right)$ :

$$
A K^{\alpha} L^{1-\alpha}-\frac{\left(\mu_{P}-1\right)}{\mu_{P}} A K^{\alpha} L^{1-\alpha}=C+I+\left(1-\frac{1}{g}\right)\left(A K^{\alpha} L^{1-\alpha}-\frac{\left(\mu_{P}-1\right)}{\mu_{P}} A K^{\alpha} L^{1-\alpha}\right),
$$

which with little algebra yields:

$$
C=\left[\frac{A}{g \mu_{P}} A\left(\left(\frac{\alpha}{1-\alpha}\right) \frac{w}{r^{k}}\right)^{\alpha}-\delta\left(\left(\frac{\alpha}{1-\alpha}\right) \frac{w}{r^{k}}\right)\right] L,
$$


where $\frac{w}{r^{k}}$ comes from Eq. (41).

Solving by repeated substitution for $L, C$, and $\Lambda$, from the system of Eqs. (44), (45) and (47), yields:

$C=\left[\frac{A}{g \mu_{P}}\left(\frac{\alpha}{1-\alpha}\right)^{\alpha-1}\left(\frac{w}{r^{k}}\right)^{\alpha}-\delta\left(\frac{w}{r^{k}}\right)\right]^{\frac{\chi}{\alpha+1}}\left(\frac{\alpha}{1-\alpha}\right)^{\frac{\chi}{\alpha+1}}\left(\frac{(1-\beta b)}{(1-b) \chi_{L} \mu_{W}} w\right)^{\frac{1}{x+1}}$,

and plugging the latter expression into $\tilde{\Lambda}$ yields:

$$
\tilde{\Lambda}=\frac{(1-\beta b)}{\left[\frac{A}{g \mu_{p}}\left(\frac{\alpha}{1-\alpha}\right)^{\alpha-1}\left(\frac{w}{r^{k}}\right)^{\alpha}-\delta\left(\frac{w}{r^{k}}\right)\right]^{\frac{\chi}{\alpha+1}}\left(\frac{\alpha}{1-\alpha}\right)^{\frac{\chi}{\alpha+1}}\left(\frac{(1-\beta b)}{(1-b) \chi_{L} \mu_{W}} w\right)^{\frac{1}{\chi^{\alpha+1}}}(1-b)},
$$

and to obtain the last unknown $L$, employ (49) and with some algebra we get:

$$
L=\left(\frac{(1-\beta b) w}{\left[\frac{A}{g \mu_{p}}\left(\frac{\alpha}{1-\alpha}\right)^{\alpha-1}\left(\frac{w}{r^{k}}\right)^{\alpha}-\delta\left(\frac{w}{r^{k}}\right)\right]\left(\frac{\alpha}{1-\alpha}\right)(1-b) \chi_{L} \mu_{W}}\right)^{\frac{1}{\alpha+1}},
$$

where $w$ and $\frac{w}{r^{k}}$ are given by Eqs. (40) and (41), respectively. Output, $Y$ at the SS is:

$$
\begin{aligned}
Y & =A K^{\alpha} L^{1-\alpha}-\frac{\left(\mu_{P}-1\right)}{\mu_{P}} A K^{\alpha} L^{1-\alpha}, \\
& =\frac{A}{\mu_{P}}\left[\left(\frac{\alpha}{1-\alpha}\right) \frac{w}{r^{k}} L\right]^{\alpha} L^{1-\alpha}=\frac{A}{\mu_{P}}\left[\left(\frac{\alpha}{1-\alpha}\right) \frac{w}{r^{k}}\right]^{\alpha} L .
\end{aligned}
$$

Then, replace $Y$ in (43) to get $F C$,

$$
F C=\frac{\left(\mu_{P}-1\right)}{\mu_{P}} A\left[\left(\frac{\alpha}{1-\alpha}\right) \frac{w}{r^{k}}\right]^{\alpha} L .
$$

Finally, calculate $G=\left(1-\frac{1}{g}\right) Y$ 


\section{The model's approximation}

The model can be represented as ${ }^{36}$ :

$$
E_{t}\left\{f\left(\mathbf{y}_{t+1}, \mathbf{y}_{t}, \mathbf{y}_{t-1}, \mathbf{v}_{t} ; \boldsymbol{\theta}\right)\right\}=\mathbf{0},
$$

which is approximated around its non-stochastic fixed point $f(\mathbf{y}, \mathbf{y}, \mathbf{y}, \mathbf{0} ; \boldsymbol{\theta})\}=\mathbf{0}$. The first order approximation of the policy function is:

$$
\mathbf{y}_{t}=\mathbf{y}+\mathbf{A} \mathbf{y}_{t-1}+\mathbf{B} \mathbf{v}_{t}
$$

Now, second order approximation of the policy function that solves the model depends on variances of shocks:

$$
\mathbf{y}_{t}=\mathbf{y}+\mathbf{A} \mathbf{y}_{t-1}+\mathbf{B} \mathbf{v}_{t}+\frac{1}{2}\left[\mathbf{y}_{t-1}^{\prime} \mathbf{C y _ { t - 1 }}+\mathbf{v}_{t}^{\prime} \mathbf{D} \mathbf{v}_{t}\right]+\mathbf{y}_{t-1}^{\prime} \mathbf{E} \mathbf{v}_{t}+\Delta \Sigma_{\mathbf{v}}
$$

where coefficients on state (exogenous) variables are contained in $\mathbf{A}(\mathbf{B})$, cross products of state (exogenous) variables are in $\mathbf{C}(\mathbf{D})$ and cross product of the state and exogenous variables are in E. Finally, $\Delta$ contains shocks' variances.

Finally, to get time variation of the variances, we solve for the third order approximation of the policy function (assume for simplicity that $g: \mathbb{R} \rightarrow \mathbb{R}^{m}$ ):

$$
g_{t}=\mathbf{y}_{t}+g_{i}\left(y_{t}^{i}-y^{i}\right)+\frac{1}{2} g_{i j}\left(y_{t}-y\right)^{i}\left(y_{t}-y\right)^{j}+\frac{1}{3 !} g_{i j l}\left(y_{t}-y\right)^{i}\left(y_{t}-y\right)^{j}\left(y_{t}-y\right)^{l}+\ldots
$$

where we employed tensor notation: $a_{i j} x^{i} y^{j} \equiv \sum_{i} \sum_{j} a_{i j} x^{i} y^{j}$ where $x^{i}$ and $y^{i}$ are collections of indexed (real) numbers by $i$ and $j$ indices. In general, $c_{j_{3}, i_{4}}^{i_{3}, i_{4}}=a_{j_{1}, j_{2}, j_{3}}^{i_{1}, i_{2}, i_{3}} b_{i_{1}, i_{2}, i_{4}}^{j_{1}, i_{2}, j_{4}} \equiv \sum_{i_{1}} \sum_{i_{2}} \sum_{j_{1}} \sum_{j_{2}} a_{j_{1}, j_{2}, j_{3}}^{i_{1}, i_{2}, i_{3}} b_{i_{1}, i_{2}, i_{4}}^{j_{1}, i_{2}, j_{4}}$ (notice that subscripts 3 and 4 remain fixed).

Now, in our case if $g: \mathbb{R}^{n} \rightarrow \mathbb{R}^{m}, \Gamma: \mathbb{R}^{m} \rightarrow \mathbb{R}^{l}$ and $h(x)=\Gamma(g(x))$, then $h: \mathbb{R}^{n} \rightarrow \mathbb{R}^{l}$. This implies that the Jacobian $h()$ is a matrix:

$$
h_{j}^{i}=\frac{\partial h^{i}}{\partial y_{j}}=\Gamma_{j}^{i} g_{j}^{l},
$$

the second derivative is a cube:

$$
h_{j l}^{i}=\frac{\partial^{2} h^{i}}{\partial y_{j} \partial y_{k}}=\Gamma_{l m}^{i} g_{k}^{m} g_{j}^{l}+\Gamma_{l}^{i} g_{j k}^{l},
$$

36 This section borrows from Judd (1998). 
and the third derivative is a 4th dimension object:

$$
\mathcal{H}_{j l l}^{i}=\frac{\partial^{3} \mathcal{H}^{i}}{\partial y_{j} \partial y_{k} \partial y_{\imath}},
$$

where $\mathcal{H}=h(\Gamma(g(x))): \mathbb{R}^{n} \rightarrow \mathbb{R}^{i}$. 
